\title{
Electrochemical monitoring of marine nutrients: From principle to application
}

\author{
Hong Wei ${ }^{\text {a, b }}$, Dawei Pan ${ }^{\text {a, b, c, *, Haitao Han }}{ }^{\text {a, c }}$ \\ ${ }^{a}$ CAS Key Laboratory of Coastal Environmental Processes and Ecological Remediation, Shandong Key Laboratory of Coastal Environmental Processes, \\ Research Center for Coastal Environment Engineering Technology of Shandong Province, Yantai Institute of Coastal Zone Research, Chinese Academy of \\ Sciences, Yantai, 264003, PR China \\ ${ }^{\mathrm{b}}$ University of Chinese Academy of Sciences, Beijing, 100049, PR China \\ ${ }^{\mathrm{c}}$ Center for Ocean Mega-Science, Chinese Academy of Sciences, Qingdao, 266071, PR China
}

\section{A R T I C L E I N F O}

\section{Article history:}

Available online 27 February 2021

\section{Keywords:}

Electrochemical detection

Nutrients

Seawater

Laboratory methodology

In situ application

\begin{abstract}
A B S T R A C T
Monitoring the spatio-temporal distribution and concentration changes of nutrients in marine environments is significant for the protection of marine ecosystems. Electrochemical technologies are ideal candidates for marine nutrient monitoring systems with the advantage of miniaturization, low reagent consumption, and easy combination with automation devices. This review assesses nutrient determination (including nitrate, nitrite, ammonium, phosphate, and silicate) using electrochemical technologies, focusing on methods for analysis of coastal, estuarine and marine water, or with specific salinity effects. The research principles, laboratory methodology and in situ application of devices are summarized. In particular, this review focuses on the response mechanism, sensitivity and detection limit of the reported sensors, with reports on in situ instruments also reviewed. Overall, this review summarizes the advances in knowledge in terms of the modes of action of devices and deployment strategies, identifying the current limitations and future challenges for the electrochemical detection of nutrients in marine environments.
\end{abstract}

() 2021 Elsevier B.V. All rights reserved.

\section{Introduction}

The major marine nutrients include nitrate, nitrite, ammonium, active phosphate, and active silicate [1]. Nutrients are the most important biogenic elements for the growth and reproduction of marine organisms, forming the basis of primary production processes and the food chain in marine environments [2,3]. For example, nitrogen and phosphorus are not only the source of metabolic energy in biological cells in marine environments, but are also important elements for cell protoplast composition [4,5], while silicon is the main element responsible for the formation of the shells and skeletons in plankton (such as diatoms) [6-8].

However, due to the rapid acceleration in urbanization, industrial and agricultural development, a large abundance of nutrients

\footnotetext{
* Corresponding author. CAS Key Laboratory of Coastal Environmental Processes and Ecological Remediation, Shandong Key Laboratory of Coastal Environmental Processes, Research Center for Coastal Environment Engineering Technology of Shandong Province, Yantai Institute of Coastal Zone Research, Chinese Academy of Sciences, Yantai 264003, PR China. Fax: +86 5352109155.

E-mail address: dwpan@yic.ac.cn (D. Pan).
}

have been directly or indirectly discharged into marine environments via industrial wastewater, agricultural waste, excessive fertilizer use, and domestic sewage [9,10]. Excessive nutrient concentrations in marine environments have resulted in an increase in eutrophication and harmful bloom events, such as red tides [11]. Excessive nutrient concentrations can directly damage marine productivity, environmental self-purification capacity and the whole ecosystem balance $[12,13]$. Therefore, accurately monitoring the spatio-temporal variation and distribution of marine nutrient concentrations is not only relevant to monitoring of marine productivity, but also significant for the early prediction of harmful marine blooms and other eutrophication associated events.

Traditionally, monitoring involves the collection of marine water samples from a monitoring site using a dedicated collection and preservation device, with samples then analyzed in land-based laboratories using specific methods. However, there are various difficulties involved in the sampling and analysis of marine water samples, as the labile components in samples change easily, such as nitrites and silicates $[14,15]$. Additionally, laboratory instruments are typically bulky, requiring complex, expensive and timeconsuming analytical methods [16]. Furthermore, traditional 
methods are unable to provide high-resolution chemical data due to the delay in detection, failing to identify transient marine events [17]. Consequently, in situ sensors are desirable for monitoring of short-term variability or long-term trend in marine nutrient concentrations. In situ nutrient sensors with high resolution, sensitivity, precision and the capacity for long-term continuous measurements are an effective way to capture small-scale spatiotemporal changes and understand temporal nutrient trends in marine ecological environments, as well as calculating the nutrient flux in coastal and estuarine zones which are affected by tidal changes and complex dynamics [18]. Accordingly, the development and application of in situ nutrient sensors are of great significance to marine environmental monitoring, the development of marine science and the enhancement of disaster warning systems. As a novel in situ method, the key issues for marine water nutrient automatic detection technologies are the application site, real-time continuous data acquisition, accuracy and convenience $[19,20]$. In the past few years, electrochemical technologies have advanced significantly, having been widely applied for marine water nutrient monitoring.

According to the differences in detection principles, in situ automatic detection devices can be divided into three categories, based on colorimetric, optical and electrochemical methods [21]. Some of the general advantages and disadvantages of these methods are listed in Table 1. Wet chemical technologies are typically based on standard colorimetric methods, which determine the target analyte at a specific wavelength based on a color reaction with an added reagent. A number of analyzers based on colorimetric methods have been proposed and used for in situ nutrient monitoring, exhibiting high accuracy and stability, as well as achieving micromolar detection levels as required for marine nutrients [22-26] However, in situ monitoring and long-term measurements require portable and environmentally-friendly equipment. Colorimetric methods have the inherent disadvantages of requiring the addition of reagents at relatively large volumes, with high levels of power typically consumed during wet chemical detection processes, resulting in these methods not being suitable for marine buoy deployment and long-term monitoring applications [27]. In contrast, ultraviolet (UV) optical sensors have the advantage of reagent-free detection, due to detection based on direct UV absorption in the environment [28,29], making these devices suitable for long-term monitoring applications in marine environments. However, to date, only nitrate can be detected using the UV optical method in marine environments. Furthermore, the working principle of all UV sensors is the measurement of light absorbance using a photometer, which is then converted to an analyte concentration [30-32], resulting in these devices being highly susceptible to turbidity, temperature and salinity variations. In addition, the sensitivity and detection limit of UV sensors are relatively poor compared to wet chemical methods. Electrochemical analysis is a qualitative and quantitative detection method based on changes in the electrochemical signals of solutions, based on the electrochemical principles of the contained substances [33-35]. At present, in situ sensors based on this method are regarded as the most promising due to their potential for rapid analysis, low energy consumption, minimal space requirements, and ease of combination with automation devices. The use of in situ electrochemical technologies has been well established for the determination of heavy metals, conductivity, $\mathrm{pH}$, and dissolved oxygen [36-40]. Electrochemical technological applications for the determination of marine nutrients are being rapidly developed and while some significant progress has been made, fully comprehending the potential of electrochemical technologies for nutrient analysis will significantly improve marine water monitoring systems.

As discussed, the electrochemical determination of nutrients and in situ applications have attracted much research attention in recent years. However, previous reviews of electrochemical techniques are typically limited to focusing on one or two nutrients [41-44], lacking a comprehensive review of electrochemical monitoring technologies for all nutrients in the marine environment. In this review, the principles of electrochemical technology applications for marine nutrients, the laboratory methodology used and the recent advances in in situ monitoring system applications are summarized. This review identifies the potentials and limitations of in situ marine electrochemical monitoring systems, with the aim of enhancing the future development of in situ sensing platforms.

\section{Principles of electrochemical techniques}

Electrochemical sensing techniques can typically be divided into three types: conductometry, amperometry/voltammetry and potentiometry. Conductometric sensors are simple to operate and are non-specific in terms of measurement species. However, most analyte concentration determinations are performed using potentiometric, voltammetric or amperometric methods due to their high selectivity, specificity and sensitivity. Potentiometry and amperometry/voltammetry methods are commonly used for the determination of nutrients, thus they are discussed in this review.

\subsection{Potentiometric device structure}

Potentiometric methods are based on measurement of the potential of an electrode system, using an indicator electrode and a

Table 1

Advantages and disadvantages of the analytical methods used for in situ determination of nutrients in marine water environments.

\begin{tabular}{|c|c|c|}
\hline Method & Advantages & Disadvantages \\
\hline Optical method & $\begin{array}{l}\text { 1. Moderately responsive } \\
\text { 2. Reagent free } \\
\text { 3. Moderate weight } \\
\text { 4. Low power consumption } \\
\text { 5. Fast response }\end{array}$ & $\begin{array}{l}\text { 1. Only for nitrate } \\
\text { 2. Real-time monitoring } \\
\text { 3. Moderate accuracy } \\
\text { 4. Biofouling }\end{array}$ \\
\hline Colorimetric method & $\begin{array}{l}\text { 1. Low limit of detection } \\
\text { 2. Large concentration range for each nutrient } \\
\text { 3. Moderate response time } \\
\text { 4. In situ calibration } \\
\text { 5. Not significantly affected by biofouling }\end{array}$ & $\begin{array}{l}\text { 1. High power requirement } \\
\text { 2. Waste generation } \\
\text { 3. Lifetime limited by reagent use and stability } \\
\text { 4. High maintenance costs }\end{array}$ \\
\hline Electrochemical method & $\begin{array}{l}\text { 1. Moderate sensitivity } \\
\text { 2. Low power consumption } \\
\text { 3. Low/no reagent use } \\
\text { 4. Fast response time } \\
\text { 5. Not influenced by turbidity }\end{array}$ & $\begin{array}{l}\text { 1. General/moderate sensitivity } \\
\text { 2. Low stability against atmospheric } \\
\text { 3. Difficult calibration } \\
\text { 4. Long measurement cycle }\end{array}$ \\
\hline
\end{tabular}


reference electrode $[45,46]$, as shown in Fig. 1A. The stability of the reference electrode is related to the change of potential difference, which is then converted to a concentration reading. An ion selective electrode (ISE) is generally used as an indicator electrode [47,48], with the ISE recognition membrane being a key component, which is composed of a specific ionophore that can recognize target ions with high selectivity $[49,50]$. ISEs are mainly divided into liquidcontact (LC) (Fig. 1B) and solid-contact (SC) (Fig. 1C). Conventional ISEs are typically based on LC, and the sensing membrane is sandwiched between two phases (the inner filling solution and the sample solution) during operation (Fig. 1D). Thus, the membrane potential is measured between two reference electrodes, most often $\mathrm{Ag}|\mathrm{AgCl}| \mathrm{Cl}^{-}$electrodes. SC ISEs are also used with a direct contact between the conducting wire and the membrane, in which the sensing membrane is sandwiched between the solid contact and the sample solution (Fig. 1E). Some cations and anions, such as $\mathrm{H}^{+}, \mathrm{Ca}^{2+}, \mathrm{K}^{+}, \mathrm{Na}^{+}, \mathrm{F}^{-}$, and $\mathrm{Cl}^{-}$, are suitable for detection using potential sensors [51]. The main advantage of ISE potentiometry is high selectivity for the target analyte. However, the selectivity of ISEs is masked for some cations (e.g. $\mathrm{NH}_{4}^{+}$) and anions (e.g. $\mathrm{NO}_{3}^{-}$) in marine water matrices due to the high concentrations of $\mathrm{Na}^{+}$and $\mathrm{Cl}^{-}$in saline water [52,53].

\subsection{Amperometric/voltammetric device structure}

An electrochemical force driven potential is applied to the electrode or solution interface, causing a chemical reaction (oxidation or reduction) and the current is recorded [54,55] with the results of current waveforms classified as voltammetric or amperometric. As shown in Fig. 2A, the system consists of a working electrode (WE), a reference electrode (RE) and a counter electrode (CE) $[56,57]$. Three-electrode systems can automatically compensate for a drop in ohmic potential in the solution, efficiently maintaining the potential of the $\mathrm{WE}$ and resulting in the potential of the RE remaining practically unchanged during the measurement process [58]. The most commonly applied REs are $\mathrm{Hg} / \mathrm{Hg}_{2} \mathrm{Cl}_{2}$, $\mathrm{Ag} / \mathrm{AgCl}$, and $\mathrm{Hg} / \mathrm{HgSO}_{4}$ electrodes, all of which exhibit good reversibility, stability and reproducibility. The function of the $\mathrm{CE}$ is to ensure that the working potential only results from the applied potential, while platinum is commonly used as CE. WE is the key part of the system where the electroactive species react. The working mechanism of the WE is shown in Fig. 2B. The measured current can be obtained by applying voltage to cause the target ion reduction or oxidation on the WE surface, thereby realizing the qualitative and quantitative analysis of the target ion. Under steady state conditions, a current-voltage profile is measured by voltametric method where the current is registered as a function of applied potential using a potentiostat. The current is measured by amperometry at a fixed potential [59]. Voltammetry has been widely used in environmental analysis as it achieves a very low detection limit, with high sensitivity and the capability for multielement recognition. Voltammetry can not only be used to accurately determine the concentration of metal ions (such as $\mathrm{Zn}^{2+}$ $\mathrm{Cd}^{2+}, \mathrm{Pb}^{2+}, \mathrm{Cu}^{2+}$, and $\left.\mathrm{Fe}^{3+}\right)[60,61]$, but also exhibits excellent nitrate, nitrite, phosphate and silicate detection performance [62-64].

\section{Laboratory methods}

\subsection{Electrochemical determination of nitrate and nitrite}

The use of electrochemical methods for the determination of nitrate was firstly reported by Faraday in 1834 [65]. Subsequently, various electrochemical sensors have been employed for environmental water analysis. Chen et al. [44] reviewed the application of electronic sensors including potentiometric, voltammetric and field-effect transistor sensors, for nitrate, nitrite, ammonium, and phosphate determination in aqueous environments and summarized their performance. Crespo et al. [66] reported the recent advances in ISE sensing platforms for environmental water analysis from on board, to in situ approaches.

\subsubsection{ISE methods}

Marine water monitoring strategies using ISEs remain a greater challenge than for freshwater monitoring, due to the high concentration of interfering ions in saline matrices (e.g. hydroxide and chloride), reducing the sensitivity and detection limit of ISEs. Accordingly, some pre-treatment strategies, such as desalination [67] or acidification [68], have been used to optimize ISE methods for the determination of nitrate and nitrite. Studies by GrygolowiczPawlak et al. [67] and Pankratova et al. [68] showed that nitrate and nitrite can be directly determined in seawater using a potentiometric method with the selective removal of excessively large concentrations of $\mathrm{Cl}^{-}$. The principle of desalination technology application was carefully verified, with the $\mathrm{Cl}^{-}$concentration effectively decreasing when the miniature sample passed through

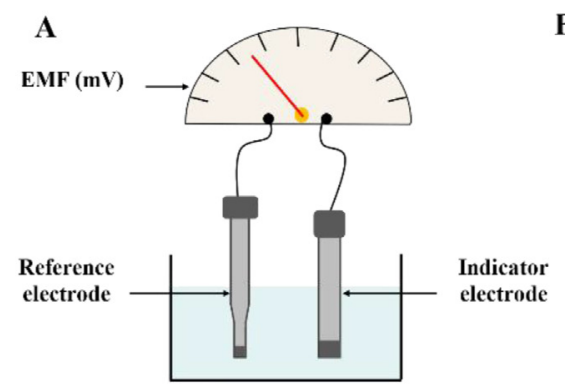

B

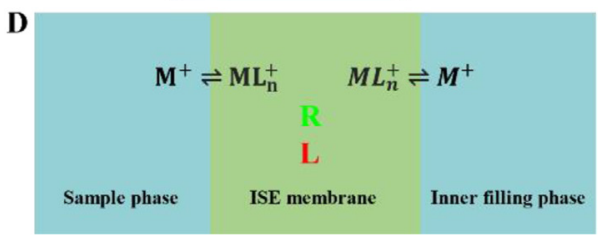

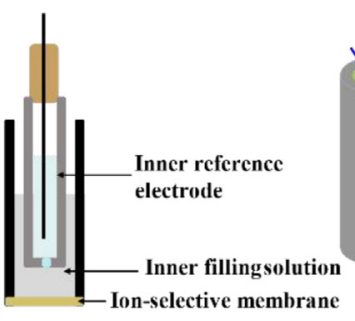

$\mathbf{E}$

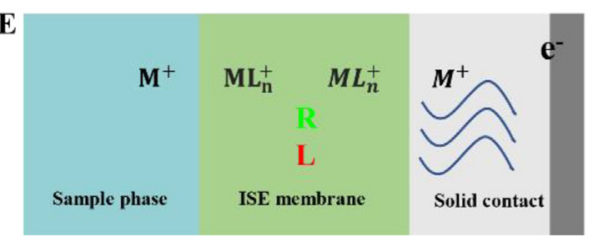

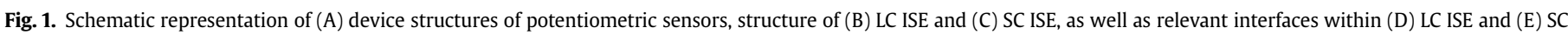
ISE $\left(\mathrm{M}^{+}\right.$is the primary ion, $\mathrm{L}$ is the ionophore, $\mathrm{R}$ is the mobile site and $\mathrm{ML}_{\mathrm{n}}^{+}$is the ionophore ion complex). 
A

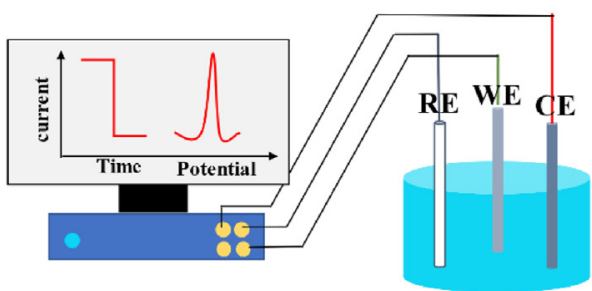

B

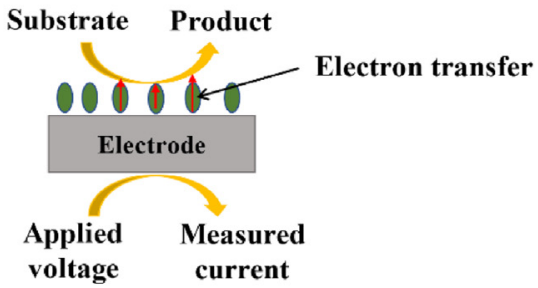

Fig. 2. A: device structures of amperometric/voltammetric sensors; B: schematic representation of WE.

the pretreatment device, while the nitrate and nitrite target concentration remained unchanged. As shown in Fig. 3A, the key component of the pretreatment device is an inner Ag working electrode. During the desalination pre-treatment process, the $\mathrm{Ag}$ working electrode functions as an anode and is oxidized, combining with $\mathrm{Cl}^{-}$to form $\mathrm{AgCl}$, while sodium counterions are transported across the Nafion membrane to the outer solution. Therefore, the pretreatment device achieves the specific $\mathrm{Cl}^{-}$removal under the steady state conditions of an electrolyte concentration gradient. After desalination pre-treatment, the concentration of $\mathrm{NaCl}$ was reduced from $0.6 \mathrm{~mol} / \mathrm{L}$ to $3 \times 10^{-3} \mathrm{~mol} / \mathrm{L}$ in a $2 \times 10^{-5} \mathrm{~L}$ sample, with the process lasting about $90 \mathrm{~s}$ and achieving an efficiency of $90 \%$. Other enhanced desalination technologies for marine water matrices have also been developed based on the principles of electrochemical technologies [69-71]. Fighera et al. [69] reported the use of printable silver inks on electrodes to integrate a microfluidic platform for the in situ desalination of marine water. At an optimum potential of $0.9 \mathrm{~V}$, the concentration of $\mathrm{NaCl}$ decreased from 0.6 to $0.206,0.157$ and $0.0516 \mathrm{~mol} / \mathrm{L}$ for oxidation times of $120 \mathrm{~s}, 240 \mathrm{~s}$ and $360 \mathrm{~s}$, respectively. The system allowed regeneration and the ability to work for 6 to 10 cycles, which is beneficial for integration with marine monitoring systems prior to nutrient detection. Acidification pre-treatment uses the suppression of hydroxide interference at the membrane surface, via three different potential strategies [68]. As shown in Fig. 3B, the protocol A achieved local acidification by passive release of acetic acid from the inner filling solution of a polyvinyl chloride (PVC) based membrane electrode. The protocol B separates an acetic acid reservoir using a fast-diffusive membrane placed in front of the indicator electrode, accomplishing local acidification. The protocol $\mathrm{C}$ utilizes the same configuration as the second strategy, except that protons are released from a diffusive hydrogen selective polymer membrane when applying constant potential. All three protocols dramatically improved the detection limit of ISEs by two orders of magnitude. Comparatively, the protocol $\mathrm{C}$ is more complex, but provides a reversible strategy with a controllable diffusion process. Overall, pre-treatment methods have a significant effect in improving the sensitivity and stability of ISEs, which is beneficial to the integration of ISEs with marine monitoring systems prior to the detection of nutrients.

Cuartero et al. [72] developed a method for the direct determination of nitrate in marine water matrices using an all-solidstate electrode coupled with an electrochemical desalination module. The schematic illustration of custom-made prototypes is shown in Fig. 3C. The electrochemical desalination module achieved a reduction of chloride concentration from $0.6 \mathrm{~mol} / \mathrm{L}$ to $2.8 \times 10^{-3} \mathrm{~mol} / \mathrm{L}$ in an $8 \times 10^{-5} \mathrm{~L}$ marine water sample. The nitrate selective electrode was successfully employed in seawater samples,

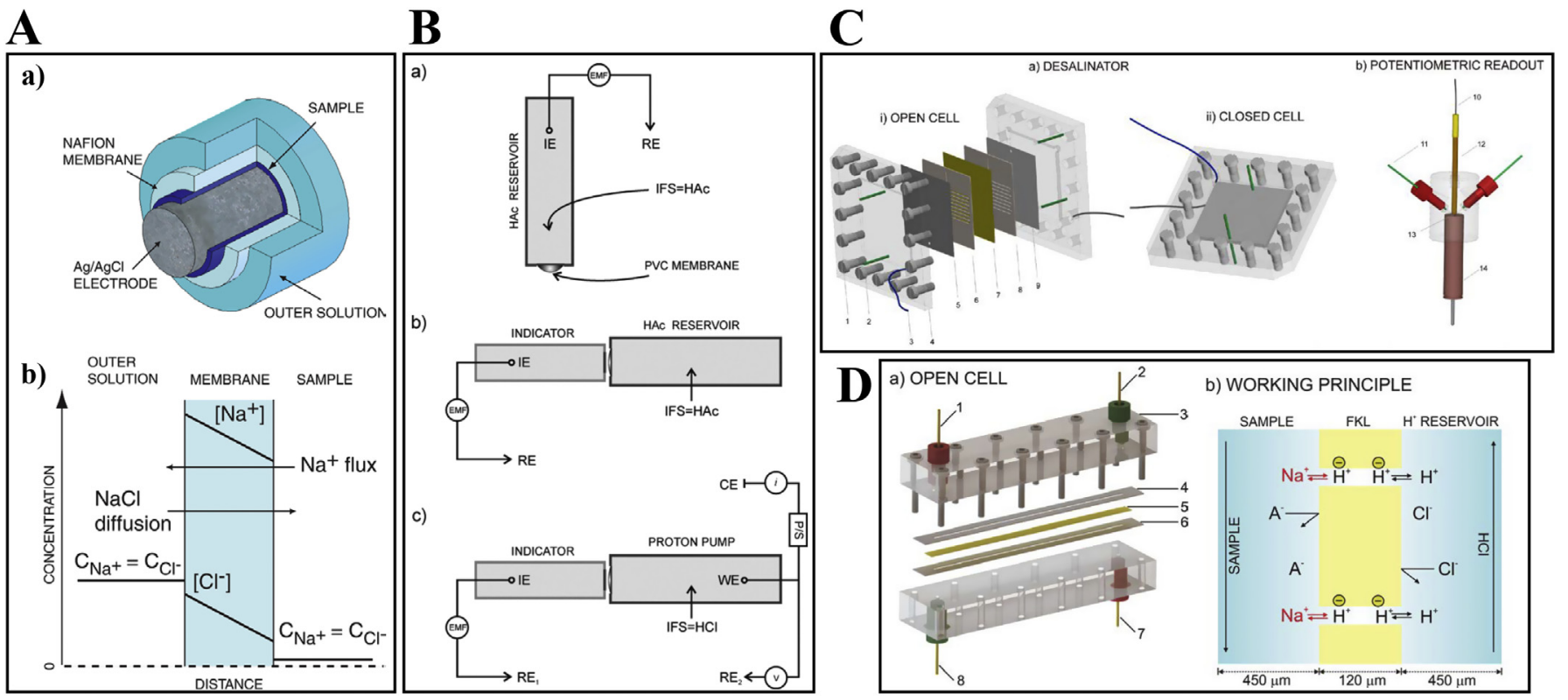

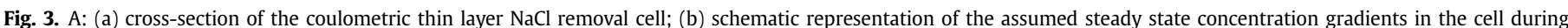

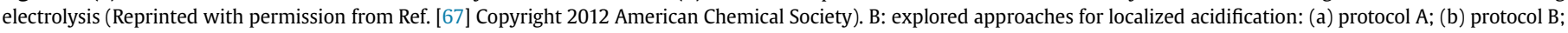

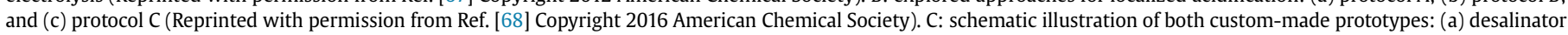

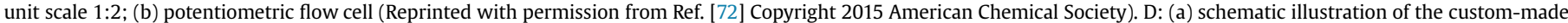

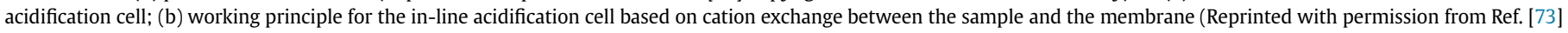
Copyright 2017 American Chemical Society). 
exhibiting a detection limit of $5 \times 10^{-7} \mathrm{~mol} / \mathrm{L}$. Pankratova et al. [73] modified the method of Cuartero et al. [72] and developed a novel approach for the potentiometric sensing of nitrite in dechlorinated seawater, using in-line acidification (Fig. 3D). The in-line acidification of the cation-exchange process between the sample and an ion-exchange Donnan exclusion membrane, effectively reducing the $\mathrm{pH}$ to $\sim 5$. The proposed method achieved the determination of nitrite without involving active sample dilution or the incorporation process. Experimental results showed that the detection limit was $5.5( \pm 0.9) \times 10^{-7} \mathrm{~mol} / \mathrm{L}$, which was improved by more than two-fold compared to under natural $\mathrm{pH}$ conditions. Overall, these studies show that the interference from marine water can be selectively removed using potentiometric technologies for nitrite and nitrate determinations.

\subsubsection{Amperometric/voltammetric methods}

The first application of voltammetry for the determination of nitrate ions traces back to the 1990s, using copper electrodes [65]. Usually, the nitrate electroreduction process primarily occurs at a negative potential of $-0.7 \mathrm{~V}$ or below, transforming nitrate to nitrite or ammonium. In contrast, nitrite can be oxidized or reduced using voltammetric or amperometric processes. In decades, voltammetric sensors for nitrate and nitrite have been developed on various electrodes, such as bare metallic surfaces (such as Pt, Pd, Ru, $\mathrm{Ir}, \mathrm{Cu}$, and $\mathrm{Ag}$ ) [74-76], polymer materials (such as polypyrrole, cesium adatoms and polystyrene) [77,78], bimetallic electrodes [79], and glass carbon electrodes. In marine water matrices, both interfering ions (such as $\mathrm{Cl}^{-}$) and side reactions (such as oxygen reactions) may lead to the unsatisfactory determinations of nitrate and nitrite. In addition, the existence of nitrite is unfavorable for electrochemical analysis of nitrate. It is of note that significant results have been made by modifying the nature of the electrode surface. In early research, Aravamudhan et al. [77] fabricated a micro-fluidic nitrate sensor modified with doped-polypyrrole nanowires (PPy-NWs). The micro-fluidic device is illustrated in Fig. 4A. The addition of PPy-NWs materials enhanced the nitrate sensor selectivity for chloride, sulfate, phosphate, and perchlorate ions. The micro-fluidic analysis setup is suitable for marine water matrix determination, with a detection limit of $4.5 \times 10^{-6} \mathrm{~mol} / \mathrm{L}$ in standard seawater samples. Following this, Fajerwerg et al. [80] designed a voltammetric sensor based on a gold electrode modified with silver nanoparticles (AgNPs/Au), which was able to directly determination of nitrate in seawater at concentration as low as $10^{-6} \mathrm{~mol} / \mathrm{L}$, without the need for pre-concentration. Additionally, the mechanism of AgNPs/Au electrode electrocatalytic reduction of nitrate was also investigated. On the basis of previous study [80], Fajerwerg et al. [81] assessed the electroactivity of the AgNPs/Au electrode for oxygen and nitrate reduction in aerated seawater. Results showed that the $\mathrm{NO}_{3}^{-}$concentration $\left(10^{-9} \mathrm{~mol} / \mathrm{L}\right)$ was successfully determined in artificial seawater without preconcentration or $\mathrm{pH}$ adjustment, with a detection limit of $9 \times 10^{-10} \mathrm{~mol} / \mathrm{L}$. Legrand et al. [82] measured nitrate concentrations in chloride solutions using an Au electrode with a controlled quantity of AgNPs. The proposed sensor was suitable for the determination of nitrate in open ocean samples with concentrations ranging from $3.9 \times 10^{-7}$ to $5 \times 10^{-5} \mathrm{~mol} / \mathrm{L}$, exhibiting good potential for in situ application. Furthermore, Li et al. [66] constructed a micro-needle nitrate sensor modified with copper microspheres and polyaniline film, which was then successfully applied to coastal river water samples, achieving a detection limit of $8 \times 10^{-6} \mathrm{~mol} / \mathrm{L}$. For nitrite, a number of detection routes and methods have been successfully used for marine water matrix applications, such as cathodic stripping voltammetry [83], graphene oxide decorated with zinc oxide on a glass carbon electrode [84] and $\mathrm{Ag} / \mathrm{Cu} / \mathrm{MWNT}$ modified electrodes (Fig. 4B) [85].

\subsection{Electrochemical determination of ammonium}

\subsubsection{ISE $\mathrm{NH}_{3} / \mathrm{NH}_{4}^{+}$sensor}

Two forms of ammonia nitrogen exist in aquatic environments: free ammonia gas $\left(\mathrm{NH}_{3}\right)$ and ammonium ions $\left(\mathrm{NH}_{4}{ }^{+}\right)$[86,87]. The ratio of these two forms of ammonia is mainly linked to the $\mathrm{pH}$ value of the water environment. When the $\mathrm{pH}$ of water $<7$ almost all of ammonia nitrogen exists in the form of $\mathrm{NH}_{4}{ }^{+}$, while under $\mathrm{pH}$ conditions of $>11$ almost all ammonia nitrogen exists as $\mathrm{NH}_{3}$. The transformation reaction between $\mathrm{NH}_{4}^{+}$and $\mathrm{NH}_{3}$ is shown in Equations (1) and (2), as follows:

$\mathrm{NH}_{3}+\mathrm{H}^{+} \rightarrow \mathrm{NH}_{4}^{+}$

$\mathrm{NH}_{4}^{+}+\mathrm{OH}^{-} \rightarrow \mathrm{NH}_{3}+\mathrm{H}_{2} \mathrm{O}$

Temperature, salinity and other factors also affect the proportion of the two forms of ammonia nitrogen in the water body [88,89]. Accordingly, ISEs can be classified into two categories: $\mathrm{NH}_{3}$ sensing electrodes or $\mathrm{NH}_{4}^{+}$sensing electrodes. $\mathrm{NH}_{3}$ sensing electrodes are based on $\mathrm{pH}$ glass electrodes for the detection of ammonia nitrogen in seawater, composed of a hydrophobic gas permeable membrane, $\mathrm{pH}$ glass electrode and $\mathrm{Ag} / \mathrm{AgCl}$ reference electrode. The basic measurement principle uses the addition of a

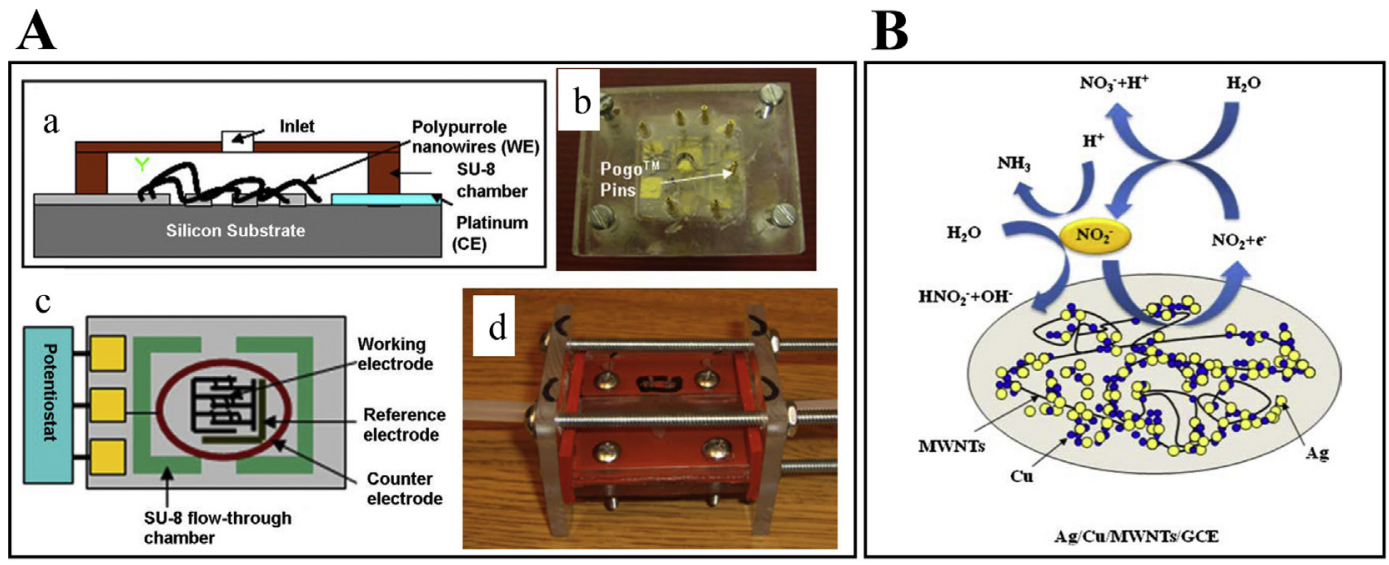

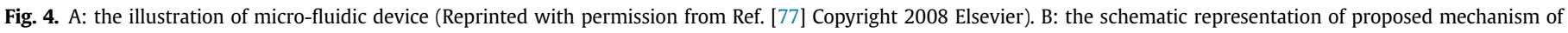
electro-oxidation of $\mathrm{NO}_{2}^{-}$at $\mathrm{Ag} / \mathrm{Cu} / \mathrm{MWNTs} / \mathrm{GCE}$ (Reprinted with permission from Ref. [85] Copyright 2018 Elsevier). 
strong alkali to increase the $\mathrm{pH}$ to above 11.0 and convert all ammonium ions in the solution into ammonia. Subsequently, ammonia is diffused into the inner filling solution of ammonium chloride through a hydrophilic permeable membrane, which causes a change in $\mathrm{H}^{+}$concentration, resulting in a potential difference, which is measured by the $\mathrm{pH}$ glass electrode. $\mathrm{NH}_{4}^{+}$sensing electrodes are composed of a PVC membrane containing an ammonium carrier. The basic measurement principle of the $\mathrm{NH}_{4}{ }^{+}$sensor is the conversion of essentially all $\mathrm{NH}_{3}$ into $\mathrm{NH}_{4}^{+}$due to acidification of the solution. Thus, the $\mathrm{NH}_{4}{ }^{+}$concentration in the sample is a result of the electrode potential of $\mathrm{NH}_{4}^{+}$on the reference electrode $(\mathrm{Ag} / \mathrm{AgCl})$ [90,91]. As early as 1973, Thomas et al. [92] used an Orion ammonia gas electrode with a multilayered gas diffusion membrane to determine ammonia in seawater, measuring ammonium at different concentrations according to the well-established addition method. It was reported that direct analysis of low concentrations (below $6 \times 10^{-7} \mathrm{~mol} / \mathrm{L}$ ) required extremely long equilibration times, with the precision, accuracy and stability in saline samples also investigated [93]. Based on the study of Tomas et al. [92,93], Merks et al. [94] tested the practical applicability of the Orion gas ammonia gas electrode in marine and estuarine water samples, focusing on the interference of $\mathrm{Cl}^{-}$. Results showed that this method was reliable for the determination of dissolved ammonia at concentrations between $6 \times 10^{-6}$ and $1 \times 10^{-3} \mathrm{~mol} / \mathrm{L}$ when an experimentally determined salinity correction was applied. Moschou et al. [95] developed a direct electrochemical flow analysis system for the simultaneous monitoring of total ammonia and nitrite concentrations in seawater using ISE probes (Fig. 5A). This system was effective for ammonia concentrations ranging from $3 \times 10^{-6}-6 \times 10^{-4} \mathrm{~mol} / \mathrm{L}$, exhibiting good reproducibility $(<5 \%)$ and stability $(<0.02 \mathrm{ppm} / \mathrm{h})$. In addition, Wen et al. [96] used an ammonium-ISE for the real-time determination of ammonia nitrogen, compensating for the $\mathrm{NH}_{4}^{+}$component of the total ammonia nitrogen fraction. The proposed sensor exhibited nearNernstian behavior at ammonia nitrogen concentrations of $6 \times 10^{-6}-6 \times 10^{-4} \mathrm{~mol} / \mathrm{L}$. However, the cationic $\mathrm{K}^{+}$ion was found to interfere with the measurement potential of ammonium-ISE, especially at low ammonia nitrogen concentrations. Therefore, it is necessary to modify determination methods using $\mathrm{K}^{+}$compensation measurements. Alternatively, to enhance the sensitivity and selectivity of ammonium sensors in marine environments, nanomaterials such as carbon nanotubes (CNTs) [97] have been applied. Jhon et al. [97] fabricated a sensor by photolithography with CNT insulation for $\mathrm{NH}_{4}^{+}$, exhibiting a low detection limit of $10^{-8} \mathrm{~mol} / \mathrm{L}$ in artificial seawater environments. Ding et al. [98] applied a SC polymeric membrane ammonium-selective electrode to determine total ammonia nitrogen in seawater samples. The electrode was integrated with a $\mathrm{pH} 7.0$ polyvinyl alcohol hydrogel buffer film and a gas-permeable membrane, resulting in higher sensitivity and a more stable response. The fabricated sensor was successfully applied in seawater with ammonia concentrations of $10^{-6}-10^{-4} \mathrm{~mol} / \mathrm{L}$ with a detection limit of $6.4 \times 10^{-7} \mathrm{~mol} / \mathrm{L}$.

\subsubsection{Voltammetric methods}

The voltammetry determination of ammonium nitrogen has rarely been reported due to its unique electrochemical stability and negative valence state of -3 . Although almost no electrochemical oxidation of ammonium occurs at a high positive potential, it can be achieved via indirect measurements. Takahashi et al. [99] proposed an indirect electrochemical method for determining ammonia nitrogen concentrations. The detection principle of this method is that bromine $\left(\mathrm{Br}_{2}\right)$ is generated by the anode, which can be hydrolyzed into hypobromic acid (HBrO) in the phosphoric acid buffer solution at $\mathrm{pH}$ 7. The schematic diagram is shown in Fig. 5B. The generated hypobromic acid can then further react with $\mathrm{NH}_{4}^{+}$in the sample in a homogeneous way, decreasing the reduction current. There is a proportional relationship between the concentration of $\mathrm{NH}_{4}^{+}$in the sample and the decrease in reduction current, allowing the ammonia nitrogen concentration to be determined according to this relationship.

In conclusion, electrochemical methods for the determination of ammonium ions have been significantly improved using novel sensing elements or structures, such as composite membranes, ionophores and nanomaterials. These fabricated sensors exhibit excellent sensitivity and rapid responses, especially at low detection limits. At present, in situ ammonium monitoring systems based on electrochemical principles have only been employed in eutrophic lakes [100] or freshwater systems [101]. Marine ammonium electrochemical in situ sensors have been rarely studied and are limited by the interference of other ions (e.g. $\mathrm{K}^{+}$and $\mathrm{Cl}^{-}$), unstable performance, poor reproducibility, and inadequate long-term reliability. Therefore, greater efforts should be applied to the development of marine ammonium electrochemical in situ sensors, with research including the practical application of sensors in marine environments.

\subsection{Electrochemical determination of phosphate}

Berchmans et al. [41] reviewed different electrochemical sensing techniques (potentiometry, voltammetry and amperometry) for the determination of inorganic phosphate and strategies using selective ionophores were discussed. Jonca et al. [26]

A

B

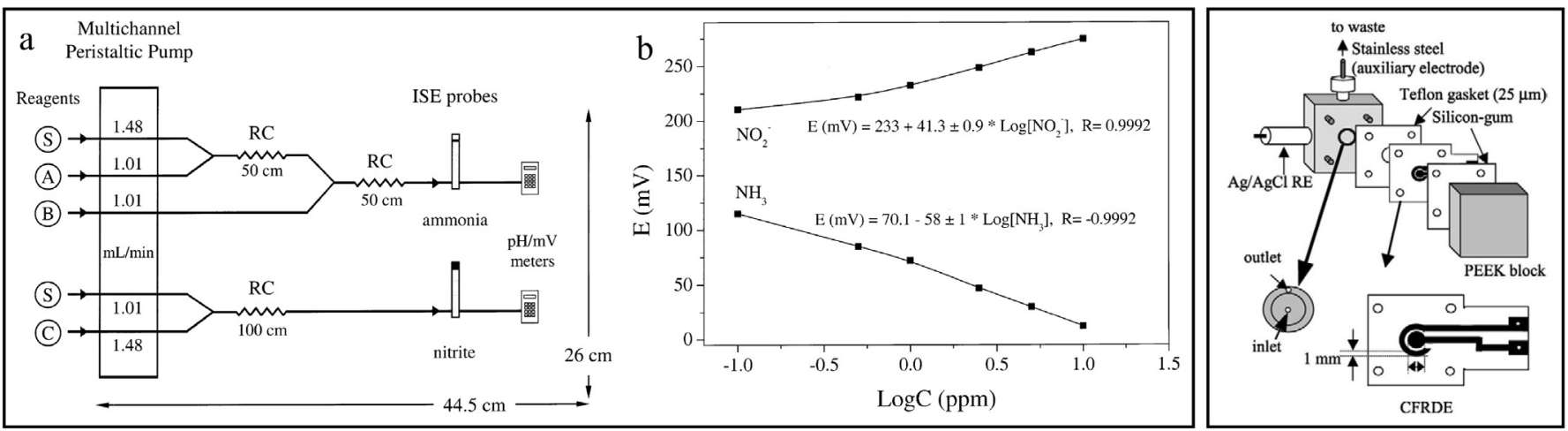

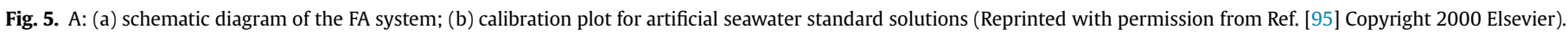
B: schematic diagram of a thin-layer electrochemical flow cell (Reprinted with permission from Ref. [99] Copyright 2008 Wiley-VCH Verlag). 
reported the present situations and trends in development of phosphate in situ analytical technologies in seawater, reporting that the existing in situ spectrophotometric sensors may be replaced by electrochemical sensors with the advantages of high precision, long application lifetimes, low detection limits, and good reproducibility.

The electrochemical principles for determination of phosphate in seawater are typically divided into two groups: (1) phosphate anion extraction into PVC-based hydrogen ion-selective membranes, with detection of the resulting membrane potential; (2) detection of the amperometry/voltammetry signals of the electroactive complex of molybdophosphate $\left(\mathrm{H}_{\mathrm{n}} \mathrm{PMo}_{12} \mathrm{O}_{40}\right)$ formed from phosphate and molybdate in acidic environments.

\subsubsection{PVC-based ISES}

The determination of phosphate using ISEs has been widely applied in environmental water analysis [102,103]. For seawater, high concentrations of the key interfering ions $\mathrm{Cl}^{-}(\sim 0.6 \mathrm{~mol} / \mathrm{L})$ and $\mathrm{OH}^{-}(\mathrm{pH} \sim 6.5-8.5)$ can mask the phosphate detection signal. Although the use of standard addition calibration can mitigate the effect of matrix complexity to some extent, it is not sufficient to ensure that phosphate determination is free from interference. An effective and simple strategy to overcome this is to optimize the ISE membrane [104,105]. Among the numerous available membranes [106,107], the ionophore-based membrane has been successfully utilized for dihydrogen phosphate detection [108]. Therefore, it remains difficult to monitor phosphate in seawater using a potentiometric sensor.

\subsubsection{Amperometric/voltammetric detection using the molybdophosphate method}

A commonly used electrochemical method for the determination of non-electroactive phosphate in marine water matrices involves the formation of a complex with molybdate, according to Equations (3) and (4) as follow:

$$
\begin{aligned}
& 7 \mathrm{H}_{3} \mathrm{PO}_{4}+12 \mathrm{Mo}_{7} \mathrm{O}_{24}^{6-}+51 \mathrm{H}^{+} \rightarrow 7 \mathrm{PMo}_{12} \mathrm{O}_{40}^{3-}+36 \mathrm{H}_{2} \mathrm{O} \\
& \mathrm{PMo}_{12} \mathrm{O}_{40}^{3-}+n \mathrm{H}^{+}+n e^{-} \rightarrow\left[\mathrm{H}_{n} \mathrm{PMo}_{12} \mathrm{O}_{40}\right]
\end{aligned}
$$

The samples are firstly reacted with a molybdate solution in an acid environment, to convert phosphate into Keggin anions $\left(\mathrm{PMo}_{12} \mathrm{O}_{40}{ }^{3-}\right)$. Then, chemical reduction results in the solution exhibiting a mixed molybdenum oxidation state. Earlier reports [109-112] showed that molybdophosphate complexes exhibit advantages in terms of redox signal stability and sensitivity, resulting in two peaks between visible at $0.1 \mathrm{~V}$ and $0.5 \mathrm{~V}$ using both voltammetric or amperometric methods. It is of note that determining how to eliminate the interfering ions is key to the successful determination of phosphate and much researches have been performed with the aim of solving this problem. Nagul et al. [113] assessed the use of the molybdenum blue reaction for the determinations of orthophosphate and described various additive and subtractive factors. Silicate is considered to be one of the main interfering factors due to its high concentrations compared to phosphate in marine environments, as well as the formation of similar molybdate complexes. Some electrochemical methods have been adopted for determination of phosphate. Matsunaga et al. [114] determined micromolar levels of orthophosphate using the molybdophosphate complex method in seawater, turbid water, and estuary water, exhibiting good precision and reproducibility. Danila Moscone et al. [115] proposed a method for the determination of orthophosphate in seawater using carbon paste microelectrodes combined with the batch injection analysis (BIA) technique, achieving a detection limit of $3 \times 10^{-7} \mathrm{~mol} / \mathrm{L}$. The scheme of the carbon paste microelectrode is presented in Fig. 6A. This method is based on the molybdophosphate signal with limited consumption of reagents, including nitric acid and ammonium molybdate. The interference of silicate was minimized by maintaining a $\left[\mathrm{H}^{+}\right] /[$molybdate] ratio of 400 . Udnan et al. [116] applied flow injection amperometry (FIA) integrated with on-line ion-exchange column pre-concentration, to determine phosphate at the carbon electrode with a limit of detection of $5.8 \times 10^{-9} \mathrm{~mol} /$ L (Fig. 6B). A significant report emphasized that autonomous amperometric detection does not require the addition of reagents, such as molybdate and nitric acid [117]. Molybdate and protons are produced during the electro-oxidation of molybdenum, which then combine with phosphate to form a molybdophosphate complex which is detected using a rotating gold disk electrode. This method was found to be effective for open ocean samples with a detection limit of $1.2 \times 10^{-7} \mathrm{~mol} / \mathrm{L}$. Reagent-free methods capable of avoiding silicate interference have been investigated, having the advantage of using differences in complex formation kinetics [118] or controlling the $\mathrm{pH}$ for complex formation $[119,120]$. Arsenate (As) is also considered to be an interfering ion. Generally, the concentration of As in oceanic seawater is relatively low [121] and its interference in phosphate determination can be ignored. However, when the concentration of As is high, a reducing agent is required to convert $\mathrm{As}(\mathrm{V})$ into $\mathrm{As}(\mathrm{III})$, avoiding As interference $[122,123]$.

\subsection{Electrochemical determination of silicate using the molybdosilicate method}

Several reports on the electrochemical determination of silicate involve the signal produced by the electro-active molybdosilicate complex (Keggin, $\mathrm{Si}\left(\mathrm{Mo}_{12} \mathrm{O}_{40}\right)^{4-}$ ). The molybdosilicate formation process is similar to that of molybdophosphate, which is formed by the reaction of silicate with molybdate under acidic conditions. The determination of silicate is not disturbed by phosphate in marine environments. Pletcher et al. [119] demonstrated the fundamental principles of the determinations of silicate and phosphate using the amperometric method. Molybdosilicate and molybdophosphate can be determined simultaneously using an Au microelectrode with phosphate and silicate concentrations in the range of $10^{-9}$ $10^{-6} \mathrm{~mol} / \mathrm{L}$. Pletcher et al. [120] also investigated the practical procedures for simultaneous determinations of silicate and phosphate on an Au microdisk electrode, provided they are present in similar concentration ranges. Jonca et al. [124-127] developed a reagent-free electrochemical method for measuring silicate in seawater using a voltammetric procedure, with the principle that molybdate and protons are provided by the electrochemical oxidation of molybdenum, which then react with silicate to form a silicon molybdenum complex. Ultramicroelectrodes and microdevices have also been used for determining oceanic silicate, which have been shown to be highly suited to in situ monitoring and longterm deployment, as these methods are simple, require low levels of energy consumption and no input of additional reagents.

\section{In situ applications}

Advancing in situ marine nutrient monitoring systems is a key focus of marine research worldwide. Electrochemical technologies are ideal for marine nutrient monitoring systems because of their low energy consumption levels, minimal space requirements, low reagent consumption, and ease of combining with automation devices. The past few decades have witnessed remarkable achievements in the monitoring of short-term variability or longterm trend in marine nutrient concentrations. 
A

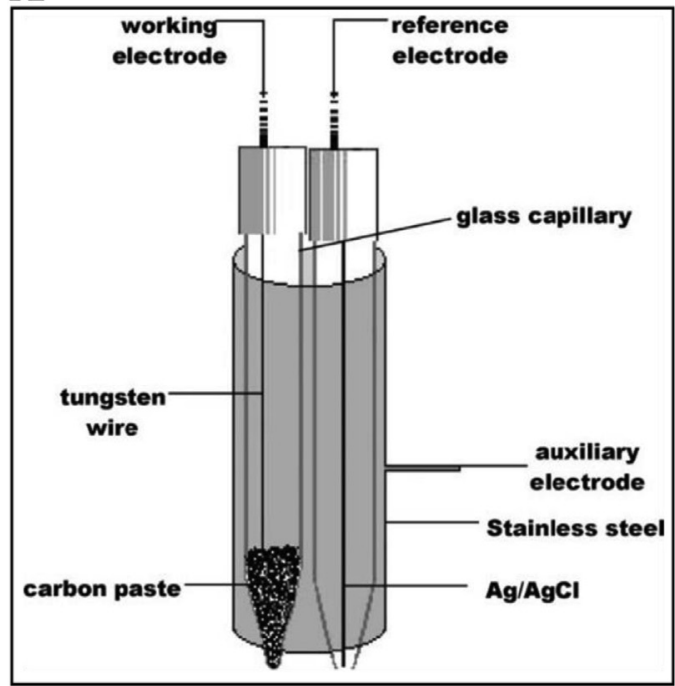

B

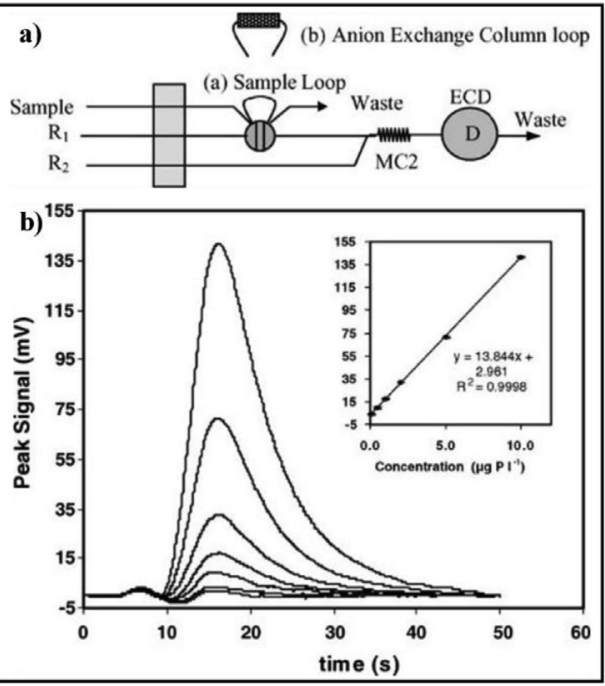

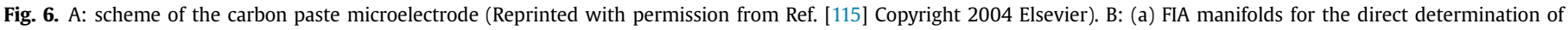
orthophosphate; (b) calibration graph of standard orthophosphate concentrations (Reprinted with permission from Ref. [116] Copyright 2005 Elsevier).

\subsection{Short-term variability monitoring systems}

An alternative in situ device was reported for submersible potentiometric detection of nitrate and nitrite in seawater [128]. As shown in Fig. 7, the developed fluidic probe consisted of three modules, a desalination module, acidification module and a potentiometric flow cell. The desalination module comprised two parts separated by a cation-exchange membrane, with the Ag foil working electrode and the reference electrode installed in two cells. The Ag foil was oxidized at a constant anodic potential, resulting in incorporation with $\mathrm{Cl}^{-}$to form $\mathrm{AgCl}$, capable of specifically eliminating interference by $\mathrm{Cl}^{-}$in seawater. The acidification module provided a suitable $\mathrm{pH}$ based on cation-exchange between the sample and the membrane. Then, the pre-treated seawater samples were analyzed by the potentiometric flow cell. It was reported that the microdevice responds within $12 \mathrm{~s}$ and had the advantage of excellent stability with long-term signal drift of less than $0.5 \mathrm{mV} \mathrm{h}^{-1}$. This device was applied to both laboratory and in situ measurements, with laboratory samples collected from different environmental regions (including Costa Calida (Spain), Plentzia (Spain) and Genoa harbor (Italy)), while the device was also deployed in situ in Arcachon Bay (France) for $23 \mathrm{~h}$ for the determinations of nitrate and nitrite. However, the submersible device operational procedure required approximately $40 \mathrm{~min}$ for desalination, acidification and potentiometric detection. Moreover, the desalination module required regular replacement. Hence, the device requires further improvement before being suitable for practical application, developing a robust desalination design.

\subsection{Long-term trend monitoring systems}

Recently, a novel autonomous reagent-free in situ electrochemical phosphate sensor was proposed by Garcon et al. $[129,130]$. This sensor was based on the common principle of the molybdophosphate method, but was innovative as molybdenum electrode oxidation automatically generated molybdate and protons in marine water instead of the additional reagents (molybdate and sulfuric acid). The process of generating molybdate and protons

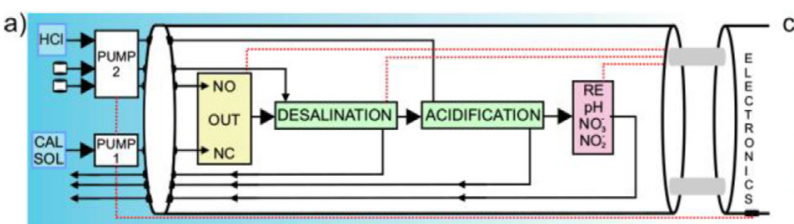

b)

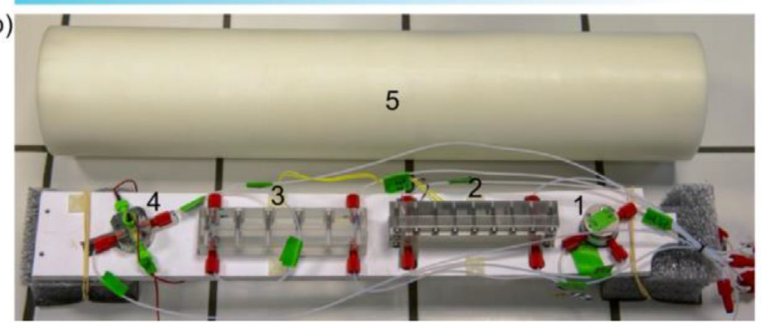

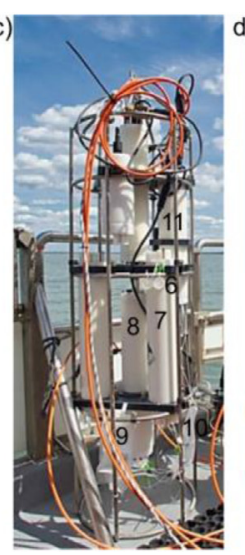

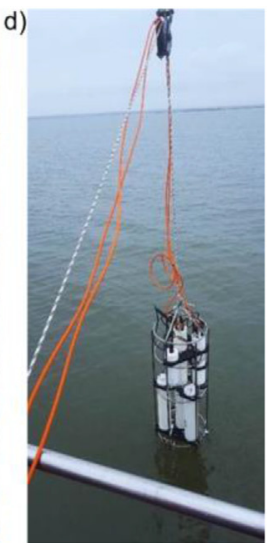

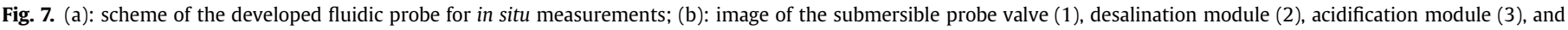

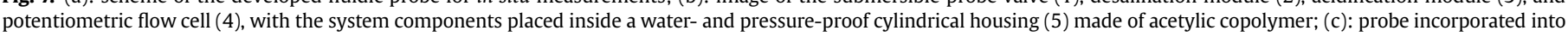

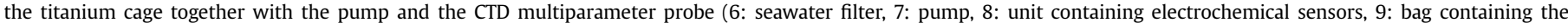

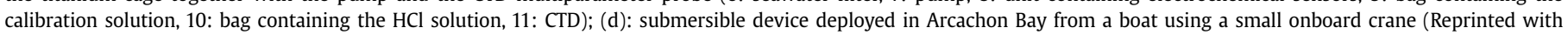
permission from Ref. [128] Copyright 2018 American Chemical Society). 
A

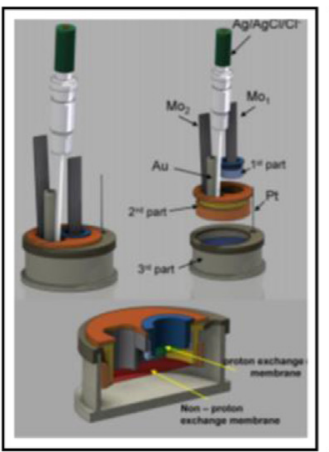

B

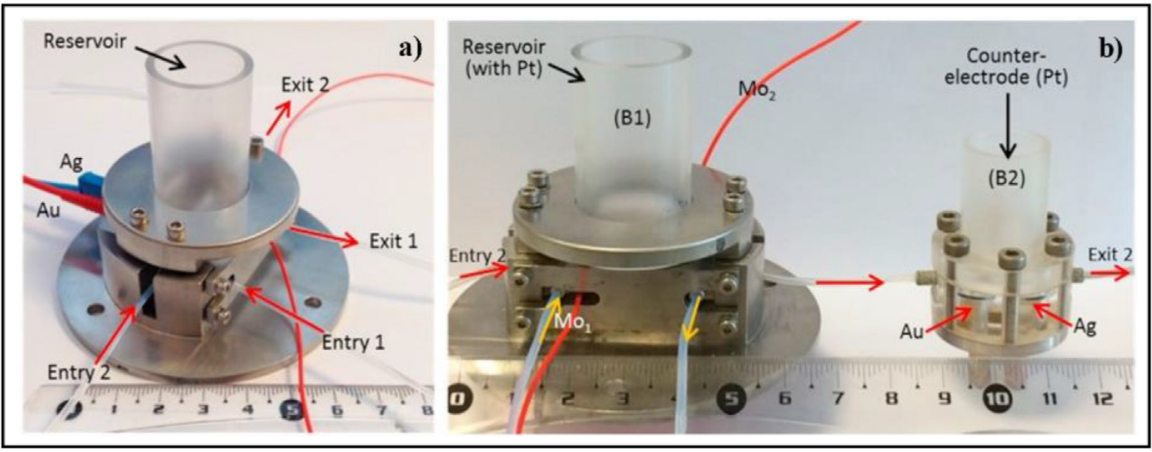

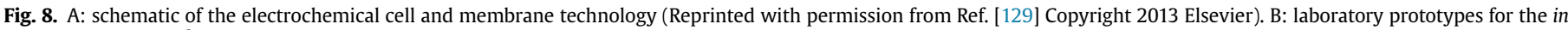

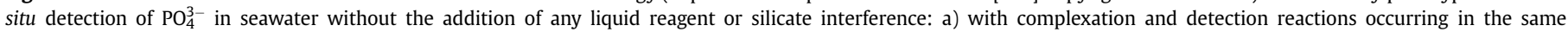
compartment; b) with separate detection compartment (Reprinted with permission from Ref. [130] Copyright 2016 Elsevier).

is caused by oxidation of the molybdenum electrode at $2 \mathrm{~V}$, as shown in Equation (5):

$\mathrm{Mo}+4 \mathrm{H}_{2} \mathrm{O} \rightarrow \mathrm{MoO}_{4}^{2-}+8 \mathrm{H}^{+}+6 e^{-}$
Since the silicate forms a molybdosilicate complex in the presence of these reagents, silicate interference can be eliminated by choosing an appropriate ratio of protons to molybdates of 70 [129]. A schematic of the electrochemical cell is illustrated in Fig. 8A, which is divided into three parts for the simultaneous production of

A

B
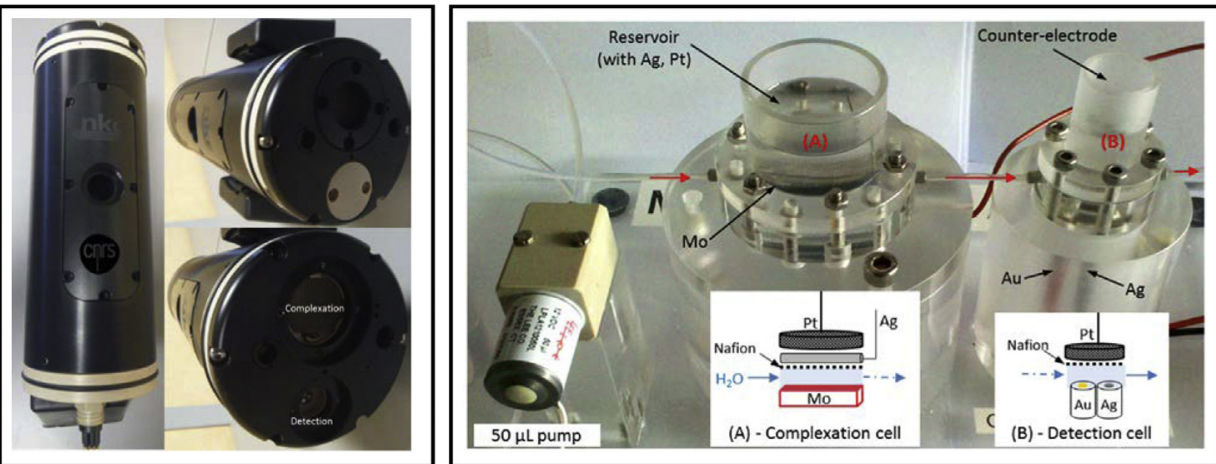

C a)

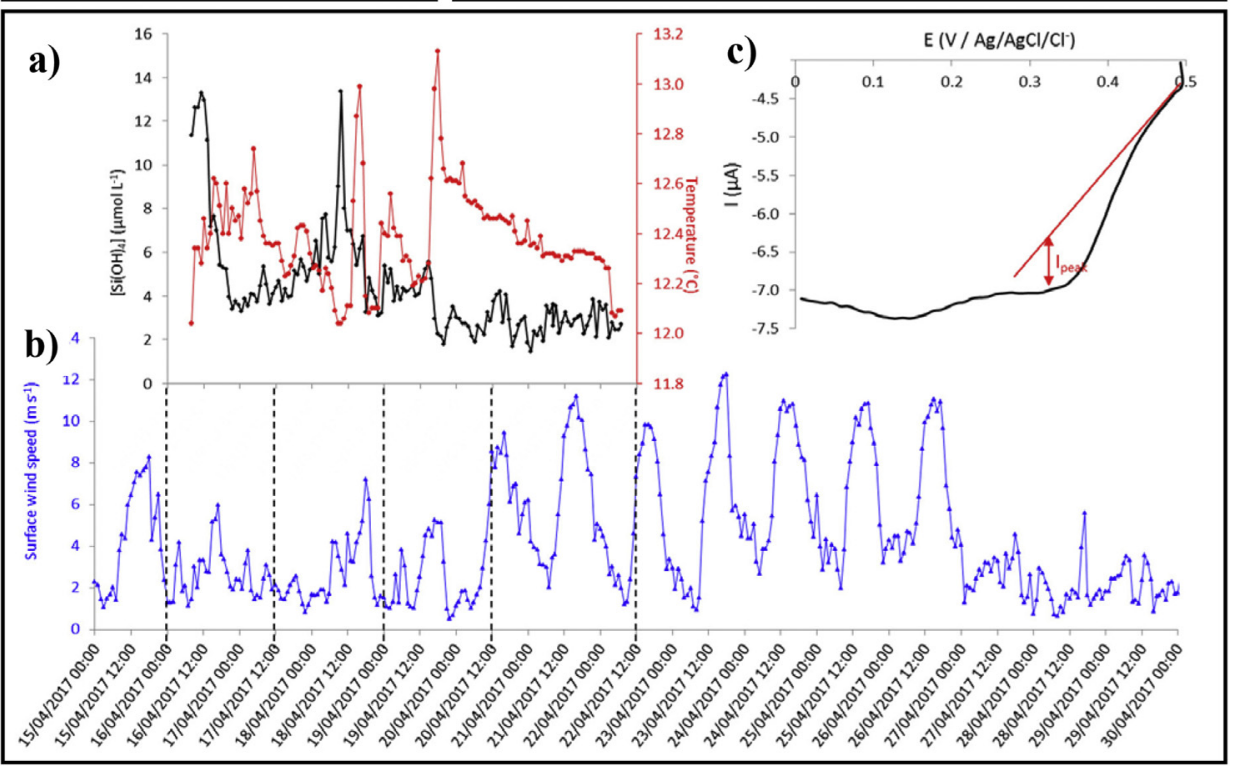

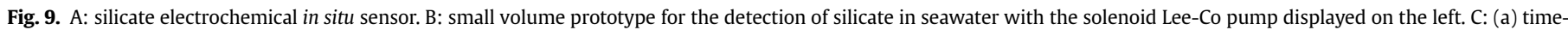

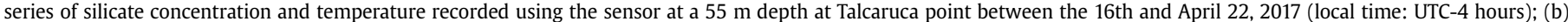

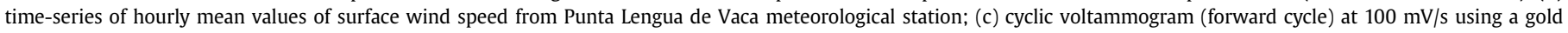
working electrode (Reprinted with permission from Ref. [131]). 
molybdate and protons at the appropriate ratio. In the first cell, oxidation of the molybdenum electrode produces excess protons, with these protons transported to the second cell using membrane technology. In the second cell, the molybdenum electrode is oxidized to achieve a proton ratio of 70 , with detection via amperometry. The third cell simulates the open ocean, containing a counter electrode to prevent $\mathrm{H}^{+}$from being reduced. Compared with colorimetric measurements, the performance of this device was tested by amperometry and different pulse voltammetry, establishing detection limits of $1.1 \times 10^{-7}$ and $1.9 \times 10^{-7} \mathrm{~mol} / \mathrm{L}$, reproducibility precision of $5.7 \%$ and $3.8 \%$, and low deviation with averages of $4.3 \%$ and $5.0 \%$, respectively.

Compared to devices with large volume compartments, small devices are designed based on laboratory prototypes (Fig. 8B). The volumetric capacity of this prototype is microliters. Square wave voltammetry at a high frequency $(\mathrm{f}=250 \mathrm{~Hz})$ allows a linear range of detection to be obtained for phosphate between $10^{-7}-10^{-6} \mathrm{~mol} /$ $\mathrm{L}$, after $60 \mathrm{~min}$ of complexation time. However, while the prototype has not been applied in the open ocean to date, considering the whole circuit time, it appears to be suitable for moorings and deepsea observations.

A submersible in situ electrochemical sensor was developed, based on the use of molybdosilicate for long-time monitoring of silicate without the need for additional reagents [131]. As presented in Fig. 9A, the silicate sensor has the advantages of miniaturization and low energy consumption, with a volume of $2.2 \mathrm{~kg}$, diameter of $90 \mathrm{~mm}$, height of $250 \mathrm{~mm}$, and power consumption of $25 \mathrm{~mA} / \mathrm{h} /$ sample. The small volume prototype $\left(<4 \times 10^{-4} \mathrm{~L}\right)$ is composed of two laboratory cells (Fig. 9B), including a complexation cell and a detection cell. In the complexation cell, molybdate and protons are generated by oxidizing the molybdenum electrode at a potential of $1 \mathrm{~V}$, then combined with silicate to form an electrochemically active molybdosilicate complex $\left(\mathrm{H}_{4} \mathrm{Si}\left(\mathrm{Mo}^{(\mathrm{VI})}{ }_{12} \mathrm{O}_{40}\right)\right)$. After this, the complex is transferred to the detection cell and quantified by cyclic voltammetry. In this configuration, the flow rate $(200-3.3 \mu \mathrm{L} / \mathrm{s})$ and complexation time (20-30 min) are the key parameters, requiring further investigation. Under optimized conditions, the detection limit of the silicate sensor was reduced to $10^{-6} \mathrm{~mol} / \mathrm{L}$, which is sufficient for the open ocean. The systems were successfully deployed in the Chilean Pacific Ocean and PROVOR float in the Mediterranean Sea (Fig. 9C). At present, only one silicate prototype has been employed in situ on different offshore moorings. Comparatively, wet chemical analyzers require reagents and produce waste during detection, while the proposed silicate sensor method does not. Thus, this in situ sensor exhibits the advantages of being suitable for long-time monitoring and deployment on different platform types for specific marine detection demands.

\section{Conclusions and outlook}

This paper reviewed the electrochemical technologies for determination of marine nutrients in terms of the analytical principle, laboratory methodology, and in situ application of devices, including the merit of deployment strategies, current limitations and future challenges. After decades of development, although the stability, sensitivity, and detection limit of sensors have greatly improved, there are still some certain technical issues that restricting the large-scale use of this technology, such as short continuous measurement time, low accuracy, narrow detection concentration ranges, and low reproducibility. Studies have shown that when some oligotrophic areas [132] or algal blooms erupt [133], the concentration of nutrients in seawater is on the order of $10^{-9} \mathrm{~mol} / \mathrm{L}$, so it is very necessary to adopt appropriate methods to increase the accuracy of the sensor. At the same time, the nutrient content in the same sea area varies greatly at different times or in different sea areas, and the concentration ranges from $10^{-9}$ to $10^{-6} \mathrm{~mol} / \mathrm{L}$, with a difference of 5 orders of magnitude [133]. Thus, an ideal electrochemical sensor needs to have wide measurement range, in addition to high accuracy.

Due to the limitation of in-situ detection conditions, the development of sensor technology tends to be small volume, low energy consumption, less reagent consumption, less wastewater output, long duration of use, and strong ion selectivity. Through interdisciplinary research with materials science, chemistry, electronics, etc., optimizing the compound process of analyzing substances, such as the application of microfluidic technology [134], is an important way to promote the miniaturization of sensors, reduce the amounts of reagents, and reduce energy consumption. At present, effective miniaturized and in situ instruments have been developed. Submersible potentiometric devices have been applied for monitoring short-term trends in marine nitrate and nitrite concentrations, and an in-situ device for phosphate and silicate determinations have been deployed on moorings offshore.

Notably, an ideal sensor also needs to have good stability, which can be achieved by improving sensor antifouling ability. At present, such approach is hot topic partially related to blood compatibility and biocompatibility in various sensors [135]. Some functional materials such as funhydrophilic polymers (e.g. poly-(ethylene glycol)), zwitterionic polymer, and antimicrobial materials (e.g. Ag nanoparticles and polycations) [136-139] have been adopted for resistance adhesive and microbial, respectively. It is fortunate that electrochemical sensors for environmental monitoring are very similar to those used for clinical or food analysis in concept. Adaptation from clinical or food analysis to the marine electrochemical sensor seems to be easy and promising. In addition, marine in situ sensors have been received extensively attention in analytical chemistry. Antifouling approaches such as bioinspired topographies (such as shark skin patterns $[140,141]$ or mollusc shell mimics [142-144]) have been performed to resist marine fouling and control cell adhesion but have rarely found application in sensors. Hence, further exploration of new antifouling materials and approaches for sensing application is expected for maintaining marine long-term sensor stability and durability.

Totally, we hope to give an important direction for the development of marine monitoring systems through this review. While there are still many limitations and challenges for the electrochemical detection of nutrients in marine environments. However, based on the advances made by numerous research groups worldwide, electrochemical techniques appear to hold much promises for practical application as marine nutrient monitoring systems.

\section{Declaration of competing interest}

The authors declare that they have no known competing financial interests or personal relationships that could have appeared to influence the work reported in this paper.

\section{Acknowledgments}

This work was financially supported by the Original Innovation Project of Chinese Academy of Sciences (ZDBS-LY-DQC009), the Strategic Priority Research Program of Chinese Academy of Sciences (XDB42000000), the National Key R\&D Program of China (2019YFD0901103). 


\section{References}

[1] J. Ma, L. Adornato, R.H. Byrne, D. Yuan, Determination of nanomolar levels of nutrients in seawater, TrAC Trends Anal. Chem. 60 (2014) 1-15. https:// doi.org/10.1016/j.trac.2014.04.013.

[2] K.R. Arrigo, Marine microorganisms and global nutrient cycles, Nature 437 (2005) 349-355. https://doi.org/10.1038/nature04265.

[3] J. Louise, C. Guieu, F. Gazeau, Nutrient dynamics under different ocean acidification scenarios in a low nutrient low chlorophyll system: the Northwestern Mediterranean Sea, Estuar. Coast Shelf Sci. 186 (2017) 30-44. https://doi.org/10.1016/j.ecss.2016.01.015.

[4] G. Song, S. Liu, J. Zhang, Z. Zhu, G. Zhang, H.K. Marchant, M.M.M. Kuypers, G. Lavik, Response of benthic nitrogen cycling to estuarine hypoxia, Limnol. Oceanogr. (2020). https://doi.org/10.1002/lno.11630.

[5] X. Zhu, J. Ma, Recent advances in the determination of phosphate in environmental water samples: insights from practical perspectives, TrAC Trends Anal. Chem. 127 (2020) 115908. https://doi.org/10.1016/j.trac.2020.115908.

[6] N. Amornthammarong, J.Z. Zhang, Liquid-waveguide spectrophotometric measurement of low silicate in natural waters, Talanta 79 (2009) 621-626. https://doi.org/10.1016/j.talanta.2009.04.050.

[7] J. Ma, R.H. Byrne, Flow injection analysis of nanomolar silicate using long pathlength absorbance spectroscopy, Talanta 88 (2012) 484-489. https:// doi.org/10.1016/j.talanta.2011.11.019.

[8] P. Rimmelin-Maury, T. Moutin, B. Queguiner, A new method for nanomolar determination of silicic acid in seawater, Anal. Chim. Acta 587 (2007) 281-286. https://doi.org/10.1016/j.aca.2007.01.055.

[9] H. Wang, G. Wang, W. Gu, Macroalgal blooms caused by marine nutrient changes resulting from human activities, J. Appl. Ecol. 57 (2020) 766-776. https://doi.org/10.1111/1365-2664.13587.

[10] H. Hong, N. Chen, D. Wang, River-estuary-coast continuum: biogeochemistry and ecological response to increasing human and climatic changes-Editorial overview, Estuar. Coast Shelf Sci. 166 (2015) 144-145. https://doi.org/ 10.1016/j.ecss.2015.10.036.

[11] J.E. Cloern, P.C. Abreu, J. Carstensen, L. Chauvaud, R. Elmgren, J. Grall, H. Greening, J.O.R. Johansson, M. Kahru, E.T. Sherwood, J. Xu, K. Yin, Human activities and climate variability drive fast-paced change across the world's estuarine-coastal ecosystems, Global Change Biol. 22 (2016) 513-529. https://doi.org/10.1111/gcb.13059.

[12] P.M. Nyenje, J.W. Foppen, S. Uhlenbrook, R. Kulabako, A. Muwanga, Eutrophication and nutrient release in urban areas of sub-Saharan Africa-A review, Sci. Total Environ. 408 (2010) 447-455. https://doi.org/10.1016/ j.scitotenv.2009.10.020.

[13] J. Zhang, S.M. Liu, J.L. Ren, Y. Wu, G.L. Zhang, Nutrient gradients from the eutrophic changjiang (yangtze river) estuary to the oligotrophic kuroshio waters and re-evaluation of budgets for the east China sea shelf, Prog. Oceanogr. 74 (2007) 449-478. https://doi.org/10.1016/j.pocean.2007.04.019.

[14] J.E. Dore, T. Houlihan, D.V. Hebel, G. Tien, L. Tupas, D.M. Karl, Freezing as a method of sample preservation for the analysis of dissolved inorganic nutrients in seawater, Mar. Chem. 53 (1996) 173-185. https://doi.org/10.1016/ 0304-4203(96)00004-7.

[15] G.T.F. Wong, L.L.T. Hou, K.Y. Li, Preservation of seawater samples for soluble reactive phosphate, nitrite, and nitrate plus nitrite analyses by the addition of sodium hydroxide, Limnol Oceanogr. Methods 15 (2017) 320-327. https://doi.org/10.1002/lom3.10160.

[16] A.M. Nightingale, A.D. Beaton, M.C. Mowlem, Trends in microfluidic systems for in situ chemical analysis of natural waters, Sensor. Actuator. B Chem. 221 (2015) 1398-1405. https://doi.org/10.1016/j.snb.2015.07.091.

[17] R.D. Prien, The future of chemical in situ sensors, Mar. Chem. 107 (2007) 422-432. https://doi.org/10.1016/j.marchem.2007.01.014.

[18] Z.A. Wang, H. Moustahfid, A.V. Mueller, A.P.M. Michel, M. Mowlem, B.T. Glazer, T.A. Mooney, W. Michaels, J.S. McQuillan, J.C. Robidart, J. Churchill, M. Sourisseau, A. Daniel, A. Schaap, S. Monk, K. Friedman, P. Brehmer, Advancing observation of ocean biogeochemistry, biology, and ecosystems with cost-effective in situ sensing technologies, Front. Mar. Sci. 6 (2019) 519. https://doi.org/10.3389/fmars.2019.00519.

[19] S. Rusjan, M. Brilly, M. Mikos, Flushing of nitrate from a forested watershed: an insight into hydrological nitrate mobilization mechanisms through seasonal high-frequency stream nitrate dynamics, J. Hydrol. 354 (2008) 187-202. https://doi.org/10.1016/j.jhydrol.2008.03.009.

[20] L. Snyder, W.B. Bowden, Nutrient dynamics in an oligotrophic arctic stream monitored in situ by wet chemistry methods, Water Resour. Res. 50 (2014) 2039-2049. https://doi.org/10.1002/2013WR014317.

[21] A. Daniel, A. Laes-Huon, C. Barus, A.D. Beaton, D. Blandfort, N. Guigues, M. Knockaert, D. Muraron, I. Salter, E.M.S. Woodward, N. Greenwood, E.P. Achterberg, Toward a harmonization for using in situ nutrient sensors in the marine environment, Front. Mar. Sci. 6 (2020) 773. https://doi.org/ 10.3389/fmars.2019.00773.

[22] A.D. Beaton, V.J. Sieben, C.F.A. Floquet, E.M. Waugh, S.A.K. Bey, I.R.G. Ogilvie, M.C. Mowlem, H. Morgan, An automated microfluidic colourimetric sensor applied in situ to determine nitrite concentration, Sensor. Actuator. B Chem. 156 (2011) 1009-1014. https://doi.org/10.1016/j.snb.2011.02.042.

[23] G.S. Clinton-Bailey, M.M. Grand, A.D. Beaton, A.M. Nightingale, D.R. Owsianka, G.J. Slavikt, D.P. Connelly, C.L. Cardwell, M.C. Mowlem, A lab-on-chip analyzer for in situ measurement of soluble reactive phosphate: improved phosphate blue assay and application to fluvial monitoring, Environ. Sci. Technol. 51 (2017) 9989-9995. https://doi.org/ 10.1021/acs.est.7b01581.

[24] X. Cao, S.W. Zhang, D.Z. Chu, N. Wu, H.K. Ma, Y. Liu, A design of spectrophotometric microfluidic chip sensor for analyzing silicate in seawater, IOP Conf. Ser. Earth Environ. Sci. 82 (2017), 012080. https://oi.org/10.1088/ 1755-1315/82/1/012080.

[25] D. Thouron, R. Vuillemin, X. Philippon, A. Lourenco, C. Provost, A. Cruzado, V. Garcon, An autonomous nutrient analyzer for oceanic long-term in situ biogeochemical monitoring, Anal. Chem. 75 (2003) 2601-2609. https:// doi.org/10.1021/ac020696+.

[26] F. Geissler, E.P. Achterberg, A.D. Beaton, M.J. Hopwood, J.S. Clarke, A. Mutzberg, M.C. Mowlem, D.P. Connelly, Evaluation of a ferrozine based autonomous in situ lab-on-chip analyzer for dissolved iron species in coastal waters, Front. Mar. Sci. 4 (2017) 322. https://doi.org/10.3389/fmars.2017.00322.

[27] M.M. Grand, A. Laes-Huon, S. Fietz, J.A. Resing, H. Obata, G.W. Luther III, A. Tagliabue, E.P. Achterberg, R. Middag, A. Tovar-Sanchez, A.R. Bowie, Developing autonomous observing systems for micronutrient trace metals, Front. Mar. Sci. 6 (2019) 35. https://doi.org/10.3389/fmars.2019.00035.

[28] M.S. Finch, D.J. Hydes, C.H. Clayson, B. Weigl, J. Dakin, P. Gwilliam, A low power ultra violet spectrophotometer for measurement of nitrate in seawater: introduction, calibration and initial sea trials, Anal. Chim. Acta 377 (1998) 167-177. https://doi.org/10.1016/S0003-2670(98)00616-3.

[29] D. Meyer, R.D. Prien, L. Rautmann, M. Pallentin, J.J. Waniek, D.E. Schulz-Bull, In situ determination of nitrate and hydrogen sulfide in the baltic sea using an ultraviolet spectrophotometer, Front. Mar. Sci. 5 (2018) 431. https:// doi.org/10.3389/fmars.2018.00431.

[30] K.S. Johnson, L.J. Coletti, In situ ultraviolet spectrophotometry for high resolution and long-term monitoring of nitrate, bromide and bisulfide in the ocean, Deep-Sea Res. Pt. I. 49 (2002) 1291-1305. https://doi.org/10.1016/ S0967-0637(02)00020-1.

[31] O. Zielinski, D. Voss, B. Saworski, B. Fiedler, A. Koertzinger, Computation of nitrate concentrations in turbid coastal waters using an in situ ultraviolet spectrophotometer, J. Sea Res. 65 (2011) 456-460. https://doi.org/10.1016/ j.seares.2011.04.002.

[32] C.M. Sakamoto, K.S. Johnson, L.J. Coletti, T.L. Maurer, G. Massion, J.T. Pennington, J.N. Plant, H.W. Jannasch, F.P. Chavez, Hourly in situ nitrate on a coastal mooring a 15-year record and insights into new production, Oceanography 30 (2017) 114-127. https://doi.org/10.5670/ oceanog.2017.428.

[33] G. Denuault, Electrochemical techniques and sensors for ocean research, Ocean Sci. 5 (2009) 697-710. https://doi.org/10.5194/os-5-697-2009. , 2009.

[34] D.R. Thevenot, K. Toth, R.A. Durst, G.S. Wilson, Electrochemical biosensors: recommended definitions and classification, Biosens. Bioelectron. 16 (2001) 121-131. https://doi.org/10.1351/pac199971122333.

[35] M. Taillefert, G.W. Luther, D.B. Nuzzio, The application of electrochemical tools for in situ measurements in aquatic systems, Electroanalysis 12 (2000) 401-412. https://doi.org/10.1002/(SICI)1521-4109(20000401)12:6<401:: AID-ELAN401>3.0.CO;2-U.

[36] K.A. Howell, E.P. Achterberg, C.B. Braungardt, A.D. Tappin, P.J. Worsfold D.R. Turner, Voltammetric in situ measurements of trace metals in coastal waters, TrAC Trends Anal. Chem. 22 (2003) 828-835. https://doi.org/ 10.1016/S0165-9936(03)01203-2.

[37] M.J. Atkinson, F.I.M. Thomas, N. Larson, E. Terrill, K. Morita, C.C. Liu, A microhole potentiostatic oxygen sensor for oceanic CTDs, Deep-Sea Res. Pt. I. 42 (1995) 761-771. https://doi.org/10.1016/0967-0637(95)00019-3.

[38] B. Maass, J. Kellner, Hydrogen clearance and cochlear microcirculation at different levels of blood-pressure, Arch. Oto-Rhino-Laryngol. 240 (1984) 295-310. https://doi.org/10.1007/BF00453385.

[39] J. Wang, D. Larson, N. Foster, S. Armalis, J.M. Lu, R.R. Xu, K. Olsen, A. Zirino, Remote electrochemical sensor for trace metal contaminants, Anal. Chem. 67 (1995) 1481-1485. https://doi.org/10.1021/ac00104a029.

[40] J.P. Cowen, D.A. Copson, J. Jolly, C.C. Hsieh, H.T. Lin, B.T. Glazer, C.G. Wheat, Advanced instrument system for real-time and time-series microbial geochemical sampling of the deep (basaltic) crustal biosphere, Deep-Sea Res. Pt. I. 61 (2012) 43-56. https://doi.org/10.1016/j.dsr.2011.11.004.

[41] S. Berchmans, T.B. Issa, P. Singh, Determination of inorganic phosphate by electroanalytical methods: a review, Anal. Chim. Acta 729 (2012) 7-20.

[42] J. Jonca, In Situ Phosphate Monitoring in Seawater: Today and Tomorrow, Springer Berlin Heidelberg, 2013. https://doi.org/10.1016/j.aca.2012.03.060.

[43] Y. Zhu, J. Chen, D. Yuan, Z. Yang, X. Shi, H. Li, H. Jin, L. Ran, Development of analytical methods for ammonium determination in seawater over the last two decades, TrAC Trends Anal. Chem. 119 (2019) 115627. https://doi.org/ 10.1016/j.trac.2019.115627.

[44] X. Chen, G. Zhou, S. Mao, J. Chen, Rapid detection of nutrients with electronic sensors: a review, Environ. Sci. Nano 5 (2018) 837-862. https://doi.org/ 10.1039/C7EN01160A.

[45] O. Isildak, O. Ozbek, Application of potentiometric sensors in real samples, Crit. Rev. Anal. Chem. (2020) 1-14. https://doi.org/10.1080/10408347.2019. 1711013.

[46] E. Bakker, E. Pretsch, P. Buhlmann, Selectivity of potentiometric ion sensors, Anal. Chem. 72 (2000) 1127-1133. https://doi.org/10.1021/ac991146n.

[47] Helmholtz, On the modern development of faraday's conception of electricity, Science 2 (1881) 182-185. https://doi.org/10.1126/science.os-2.44.182. 
[48] R. DeMarco, G. Clarke, B. Pejcic, Ion-selective electrode potentiometry in environmental analysis, Electroanalysis 19 (2007) 1987-2001. https:// doi.org/10.1002/elan.200703916.

[49] A. Volkov, E. Gorbova, A. Vylkov, D. Medvedev, A. Demin, P. Tsiakaras, Design and applications of potentiometric sensors based on proton-conducting ceramic materials. A brief review, Sensor. Actuator. B Chem. 244 (2017) 1004-1015. https://doi.org/10.1016/j.snb.2017.01.097.

[50] T. Yin, W. Qin, Applications of nanomaterials in potentiometric sensors, TrAC Trends Anal. Chem. 51 (2013) 79-86. https://doi.org/10.1016/j.trac.2013.06. 009.

[51] D.D. Beer, A. Bissett, R.D. Wit, H. Jonkers, S. Koehler-Rink, H. Nam, B.H. Kim, G. Eickert, M. Grinstain, A microsensor for carbonate ions suitable for microprofiling in freshwater and saline environments, Limnol Oceanogr. Methods 6 (2008) 532-541. https://doi.org/10.4319/lom.2008.6.532.

[52] E. Bakker, E. Pretsch, Modern potentiometry, Angew. Chem. Int. Ed. 46 (2007) 5660-5668. https://doi.org/10.1002/anie.200605068.

[53] E. Zdrachek, E. Bakker, Potentiometric sensing, Anal. Chem. 91 (2019) 2-26.

[54] R. Seeber, L. Pigani, F. Terzi, C. Zanardi, Amperometric sensing. a melting pot for material, electrochemical, and analytical sciences, Electrochim. Acta 179 (2015) 350-363. https://doi.org/10.1016/j.electacta.2015.03.074.

[55] A.M. Bond, D. Elton, S.X. Guo, G.F. Kennedy, E. Mashkina, A.N. Simonov, J. Zhang, An integrated instrumental and theoretical approach to quantitative electrode kinetic studies based on large amplitude Fourier transformed a.c. voltammetry: a mini review, Electrochem. Commun. 57 (2015) 78-83. https://doi.org/10.1016/j.elecom.2015.04.017.

[56] J. Wang, Electrochemistry for environmental science and technology, Denki Kagaku 66 (1998). https://doi.org/10.5796/kogyobutsurikagaku.66.577, 577577.

[57] V. Mirceski, R. Gulaboski, M. Lovric, I. Bogeski, R. Kappl, M. Hoth, Squarewave voltammetry: a review on the recent progress, Electroanalysis 25 (2013) 2411-2422. https://doi.org/10.1002/elan.201300369.

[58] C. Arino, N. Serrano, J.M. Diaz-Cruz, M. Esteban, Voltammetric determination of metal ions beyond mercury electrodes. A review, Anal. Chim. Acta 990 (2017) 11-53. https://doi.org/10.1016/j.aca.2017.07.069.

[59] G. Herzog, V. Beni, Stripping voltammetry at micro-interface arrays: a review, Anal. Chim. Acta 769 (2013) 10-21. https://doi.org/10.1016/j.aca.2012. 12.031.

[60] M. Lin, X. Hu, D. Pan, H. Han, Determination of iron in seawater: from the laboratory to in situ measurements, Talanta 188 (2018) 135-144. https:// doi.org/10.1016/j.talanta.2018.05.071.

[61] E. Bernalte, S. Arevalo, J. Perez-Taborda, J. Wenk, P. Estrela, A. Avila, M.D. Lorenzo, Rapid and on-site simultaneous electrochemical detection of copper, lead and mercury in the Amazon river, Sensor. Actuator. B Chem. 307 (2020) 127620. https://doi.org/10.1016/j.snb.2019.127620.

[62] M. Pumera, A. Ambrosi, A. Bonanni, E.L.K. Chng, H.L. Poh, Graphene for electrochemical sensing and biosensing, Trac. Trends Anal. Chem. 29 (2010) 954-965. https://doi.org/10.1016/j.trac.2010.05.011.

[63] M.B. Gumpu, S. Sethuraman, U.M. Krishnan, J.B.B. Rayappan, A review on detection of heavy metal ions in water-An electrochemical approach, Sensor. Actuator. B Chem. 213 (2015) 515-533. https://doi.org/10.1016/j.snb.2015. 02.122.

[64] M.J. Moorcroft, J. Davis, R.G. Compton, Detection and determination of nitrate and nitrite: a review, Talanta 54 (2001) 785-803. https://doi.org/ 10.1016/S0039-9140(01)00323-X.

[65] L.P. Williams, Experimental researches in electricity, Science 150 (1965) 598-599. https://doi.org/10.1126/science.150.3696.598-b.

[66] G.A. Crespo, Recent Advances in ion-selective membrane electrodes for in situ environmental water analysis, Electrochim. Acta 245 (2017) 1023-1034. https://doi.org/10.1016/j.electacta.2017.05.159.

[67] E. Grygolowicz-Pawlak, M. Sohail, M. Pawlak, B. Neel, A. Shvarev, R.D. Marco, E. Bakker, Coulometric sodium chloride removal system with nafion membrane for seawater sample treatment, Anal. Chem. 84 (2012) 6158-6165. https://doi.org/10.1021/ac301096r.

[68] N. Pankratova, M.G. Afshar, D. Yuan, G.A. Crespo, E. Bakker, Local acidification of membrane surfaces for potentiometric sensing of anions in environmental samples, ACS Sens. 1 (2016) 48-54. https://doi.org/ 10.1021/acssensors.5b00015.

[69] M. Fighera, P.D. van der Wal, H. Shea, Microfluidic platform for seawater desalination by coulometric removal of chloride ions through printed $\mathrm{Ag}$ electrodes, J. Electrochem. Soc. 164 (2017) H836-H845. https://doi.org/ $10.1149 / 2.1761712$ jes.

[70] J. Ahn, J. Lee, S. Kim, C. Kim, J. Lee, P.M. Biesheuvel, J. Yoon, High performance electrochemical saline water desalination using silver and silver-chloride electrodes, Desalination 476 (2020) 114216. https://doi.org/10.1016/ j.desal.2019.114216.

[71] M. Cuartero, G.A. Crespo, E. Bakker, Paper-based thin-layer coulometric sensor for halide determination, Anal. Chem. 87 (2015) 1981-1990. https:// doi.org/10.1021/ac504400w.

[72] M. Cuartero, G.A. Crespo, E. Bakker, Tandem electrochemical desalinationpotentiometric nitrate sensing for seawater analysis, Anal. Chem. 87 (2015) 8084-8089. https://doi.org/10.1021/acs.analchem.5b01973.

[73] N. Pankratova, M. Cuartero, T. Cherubini, G.A. Crespo, E. Bakker, In-line acidification for potentiometric sensing of nitrite in natural waters, Anal. Chem. 89 (2017) 571-575. https://doi.org/10.1021/acs.analchem. $6 b 03946$.
[74] G.E. Dima, A.C.A. De Vooys, M.T.M. Koper, Electrocatalytic reduction of nitrate at low concentration on coinage and transition-metal electrodes in acid solutions, J. Electroanal. Chem. 554 (2003) 15-23. https://doi.org/10.1016/ S0022-0728(02)01443-2.

[75] J. Davis, M.J. Moorcroft, S.J. Wilkins, R.G. Compton, M.F. Cardosi, Electrochemical detection of nitrate and nitrite at a copper modified electrode Analyst 125 (2000) 737-742. https://doi.org/10.1039/A909762G.

[76] J.T. Matsushima, W.M. Silva, A.F. Azevedo, M.R. Baldan, N.G. Ferreira, The influence of boron content on electroanalytical detection of nitrate using BDD electrodes, Appl. Surf. Sci. 256 (2009) 757-762. https://doi.org/10.1016/ j.apsusc.2009.08.055.

[77] S. Aravamudhan, S. Bhansali, Development of micro-fluidic nitrate-selective sensor based on doped-polypyrrole nanowires, Sensor. Actuator. B Chem. 132 (2008) 623-630. https://doi.org/10.1016/j.snb.2008.01.046.

[78] M.C. Tsai, D.X. Zhuang, P.Y. Chen, Electrodeposition of macroporous silver films from ionic liquids and assessment of these films in the electrocatalytic reduction of nitrate, Electrochim. Acta 55 (2010) 1019-1027. https://doi.org/ 10.1016/j.electacta.2009.09.070.

[79] S. Piao, Y. Kayama, Y. Nakano, N. Kou, Y. Yoshinaga, K. Shimazu, Nitrate reduction on tin-modified rhodium, ruthenium, and iridium electrodes, J. Electroanal. Chem. 629 (2009) 110-116. https://doi.org/10.1016/ j.jelechem.2009.01.031

[80] K. Fajerwerg, V. Ynam, B. Chaudret, V. Garcon, D. Thouron, M. Comtat, An original nitrate sensor based on silver nanoparticles electrodeposited on a gold electrode, Electrochem. Commun. 12 (2010) 1439-1441. https:// doi.org/10.1016/j.elecom.2010.08.003.

[81] E. Lebon, P. Fau, M. Comtat, M.L. Kahn, A. Sournia-Saquet, P. TempleBoyer, B. Dubreuil, P. Behra, K. Fajerwerg, In situ metalorganic deposition of silver nanoparticles on gold substrate and square wave voltammetry: a highly efficient combination for nanomolar detection of nitrate ions in sea water, Chemosensors 6 (2018) 50. https://doi.org/10.3390/ chemosensors6040050.

[82] D.C. Legrand, C. Barus, V. Garcon, Square wave voltammetry measurements of low concentrations of nitrate using $\mathrm{Au} / \mathrm{AgNPs}$ electrode in chloride solutions, Electroanalysis 12 (2017) 2882-2887. https://doi.org/10.1002/elan. 201700447.

[83] C.M.G. Van Den Berg, H. Li, The determination of nanomolar levels of nitrite in fresh and sea-water by cathodic stripping voltammetry, Anal. Chim. Acta 212 (1988) 31-41. https://doi.org/10.1016/S0003-2670(00)84126-4.

[84] A.R. Marlinda, A. Pandikumar, N. Yusoff, N.M. Huang, H.N. Lim, Electrochemical sensing of nitrite using a glassy carbon electrode modified with reduced functionalized graphene oxide decorated with flower-like zinc oxide, Microchim. Acta 182 (2015) 1113-1122. https://doi.org/10.1007/ s00604-014-1436-X.

[85] Y. Zhang, J. Nie, H. Wei, H. Xu, Q. Wang, Y. Cong, J. Tao, Y. Zhang, L. Chu, Y. Zhou, X. Wu, Electrochemical detection of nitrite ions using $\mathrm{Ag} / \mathrm{Cu} / \mathrm{MWNT}$ nanoclusters electrodeposited on a glassy carbon electrode, Sensor. Actuator. B Chem. 258 (2018) 1107-1116. https://doi.org/10.1016/j.snb.2017.12.001.

[86] L. Zhou, C.E. Boyd, Comparison of nessler, phenate, salicylate and ion selective electrode procedures for determination of total ammonia nitrogen in aquaculture, Aquaculture 450 (2016) 187-193. https://doi.org/10.1016/ j.aquaculture.2015.07.022.

[87] R.K. Larsen, J.C. Steinbacher, J.E. Baker, Ammonia exchange between the atmosphere and the surface waters at two locations in the chesapeake Bay, Environ. Sci. Technol. 35 (2001) 4731-4738. https://doi.org/10.1021/ es0107551.

[88] R.P. Trussell, Percent un-ionized ammonia in aqueous ammonia solutions at different $\mathrm{pH}$ levels and temperatures, J. Fish. Res. Board Can. 29 (1972) 1505-1507. https://doi.org/10.1139/f72-236.

[89] K. Emerson, R.C. Russo, R.E. Lund, R.V. Thurston, Aqueous ammonia equilibrium calculations-effect of pH and temperature, J. Fish. Res. Bd. 32 (1975) 2379-2383, https://doi.org/10.1139/f75-274.

[90] C.F.B. Coutinho, A.A. Muxel, C.G. Rocha, D.A. de Jesus, R.V.S. Alfaya, F.A.S. Almeida, Y. Gushikem, A.A.S. Alfaya, Ammonium ion sensor based on $\mathrm{SiO}_{2} / \mathrm{ZrO}_{2} /$ phosphate- $\mathrm{NH}_{4}^{+}$composite for quantification of ammonium ions in natural waters, J. Braz. Chem. Soc. 18 (2007) 189-194. https://doi.org/ 10.1590/S0103-50532007000100022.

[91] U. Bende-Michl, P.B. Hairsine, A systematic approach to choosing an automated nutrient analyser for river monitoring, J. Environ. Monit. 12 (2010) 127-134. https://doi.org/10.1039/B910156J.

[92] T.R. Gilbert, A.M. Clay, Determination of ammonia in aquaria and in sea water using the ammonia electrode, Anal. Chem. 45 (1973) 1757-1759. https://doi.org/10.1021/ac60331a038.

[93] R.F. Thomas, R.L. Booth, Selective electrode measurement of ammonia in water and wastes, Environ. Sci. Technol. 7 (1973) 523-526. https://doi.org/ 10.1021/es60078a006.

[94] A.G.A. Merks, Determination of ammonia in sea water with an ion-selective electrode, Neth. J. Sea Res. 9 (1975) 371-375. https://doi.org/10.1016/00777579(75)90011-3.

[95] E.A. Moschou, U.A. Lasarte, M. Fouskaki, N.A. Chaniotakis, N. Papandroulakis, P. Divanach, Direct electrochemical flow analysis system for simultaneous monitoring of total ammonia and nitrite in seawater, Aquacult. Eng. 22 (2000) 255-268. https://doi.org/10.1016/S0144-8609(00)00053-4.

[96] Y. Wen, Y. Mao, Z. Kang, Q. Luo, Application of an ammonium ion-selective electrode for the real-time measurement of ammonia nitrogen based on 
pH and temperature compensation, Measurement 137 (2019) 98-101. https://doi.org/10.1016/j.measurement.2019.01.031.

[97] C.W. Jang, Y.T. Byun, Y.M. Jhon, Detection of $10 \mathrm{nM}$ ammonium ions in 35 parts per thousand $\mathrm{NaCl}$ solution by carbon nanotube based sensors, J. Nanosci. Nanotechnol. 12 (2012) 1765-1769. https://doi.org/10.3390/ s130607827.

[98] L. Ding, J. Ding, B. Ding, W. Qin, Solid-contact potentiometric sensor for the determination of total ammonia nitrogen in seawater, Int. J. Electrochem. Sci. 12 (2017) 3296-3308. https://doi.org/10.20964/2017.04.01.

[99] M. Takahashi, K. Nakamura, J. Jin, Study on the indirect electrochemical detection of ammonium ion with in situ electrogenerated hypobromous acid, Electroanalysis 20 (2008) 2205-2211. https://doi.org/10.1002/ elan.200804311.

[100] R. Athavale, I. Kokorite, C. Dinkel, E. Bakker, B. Wehrli, G.A. Crespo, A. Brand, In situ ammonium profiling using solid-contact ion-selective electrodes in eutrophic lakes, Anal. Chem. 87 (2015) 11990-11997. https://doi.org/ 10.1021/acs.analchem.5b02424.

[101] R. Athavale, C. Dinkel, B. Wehrli, E. Bakker, G.A. Crespo, A. Brand, Robust solid-contact ion selective electrodes for high-resolution in situ measurements in fresh water systems, Environ. Sci. Technol. Lett. 4 (2017) 286-291. https://doi.org/10.1021/acs.estlett.7b00130.

[102] E. Bakker, Electroanalysis with membrane electrodes and liquid-liquid interfaces, Anal. Chem. 88 (2015) 395-413. https://doi.org/10.1021/acs.analchem.5b04034.

[103] C. Zuliani, D. Diamond, Opportunities and challenges of using ion-selective electrodes in environmental monitoring and wearable, Sensors 84 (2012) 29-34. https://doi.org/10.1016/j.electacta.2012.04.147.

[104] A. Michalska, J. Dumańska, K. Maksymiuk, Lowering the detection limit of ion selective plastic membrane electrodes with conducting polymer solid contact and conducting polymer potentiometric sensors, Anal. Chem. 75 (2003) 4964-4974. https://doi.org/10.1021/ac034335l.

[105] D. Yuan, A.H.C. Anthis, M.G. Afshar, N. Pankratova, M. Cuartero, G.A. Crespo, E. Bakker, All-solid-state potentiometric sensors with multi-walled carbon nanotube inner transducing layer for anion detection in environmental samples, Anal. Chem. 87 (2015) 8640-8645. https://doi.org/10.1021/ acs.analchem.5b01941.

[106] M.R. Ganjali, P. Norouzi, M. Ghomi, M. Salavati-Niasari, Highly selective and sensitive monohydrogen phosphate membrane sensor based on molybdenum acetylacetonate, Anal. Chim. Acta 567 (2006) 196-201. https://doi.org/ 10.1016/j.aca.2006.03.026.

[107] A.K. Jain, V.K. Gupta, J.R. Raisoni, A newly synthesized macrocyclic dithioxamide receptor for phosphate sensing, Talanta 69 (2006) 1007-1012. https://doi.org/10.1016/j.talanta.2005.12.023.

[108] S. Sateanchok, N. Pankratova, M. Cuartero, T. Cherubini, K. Grudpan, E. Bakker, In-line seawater phosphate detection with ion-exchange membrane reagent delivery, ACS Sens. 11 (2018) 2455-2462. https://doi.org/ 10.1021/acssensors.8b01096.

[109] A.G. Fogg, N.K. Bsebsu, B.J. Birch, Differential-pulse anodic voltammetric determination of phosphate, silicate, arsenate and germanate as $\beta$-heteropolymolybdates at a stationary glassy-carbon electrode, Talanta 28 (1981) 473-476. https://doi.org/10.1016/0039-9140(81)80071-9.

[110] A.G. Fogg, G.C. Cripps, B.J. Birch, Static and flow-injection voltammetric determination of total phosphate and soluble silicate in commercial washing powders at a glassy-carbon electrode, Analyst 108 (1983) 1485-1489. https://doi.org/10.1039/AN9830801485.

[111] A.G. Fogg, N.K. Bsebsu, Sequential flow-injection voltammetric determination of phosphate and nitrite by injection of reagents into a sample stream, Analyst 109 (1984) 19-21. https://doi.org/10.1039/AN9840900019.

[112] A.G. Fogg, S.P. Scullion, T.E. Edmonds, B.J. Birch, Adaptation of on-line reactions developed for use with flow injection with amperometric detection for use in disposable sensor devices: reductive determination of phosphate as preformed 12-molybdophosphate in a capillary-fill device, Analyst 115 (1990) 1277-1281. https://doi.org/10.1039/AN9901501277.

[113] E.A. Nagul, I.D. Mckelvie, P. Worsfold, S.D. Kolev, The molybdenum blue reaction for the determination of orthophosphate revisited: opening the black box, Anal. Chim. Acta 890 (2015) 60-82. https://doi.org/10.1016/ j.aca.2015.07.030.

[114] K. Matsunaga, I. Kudo, M. Yanada, K. Hasebe, Differential-pulse anodic voltammetric determination of dissolved and adsorbed phosphate in turbid natural waters, Anal. Chim. Acta 185 (1986) 355-358. https://doi.org/ 10.1016/0003-2670(86)80066-6.

[115] J.C. Quintana, L. Idrissi, G. Palleschi, P. Albertano, A. Amine, M.E. Rhazi, D. Moscone, Investigation of amperometric detection of phosphate: application in seawater and cyanobacterial biofilm samples, Talanta 63 (2004) 567-574. https://doi.org/10.1016/j.talanta.2003.11.040.

[116] Y. Udnan, I.D. Mckelvie, M.R. Grace, J. Jakmunee, K. Grudpan, Evaluation of on-line preconcentration and flow-injection amperometry for phosphate determination in fresh and marine waters, Talanta 66 (2005) 461-466. https://doi.org/10.1016/j.talanta.2004.12.064.

[117] J. Jonca, V.L. Fernandez, D. Thouron, A. Paulmier, M. Graco, V. Garcon, Phosphate determination in seawater: toward an autonomous electrochemical method, Talanta 87 (2011) 161-167. https://doi.org/10.1016/ j.talanta.2011.09.056.
[118] J.Z. Zhang, C.H. Fischer, P.B. Ortner, Optimization of performance and minimization of silicate interference in continuous flow phosphate analysis, Talanta 49 (1999) 293-304. https://doi.org/10.1016/S0039-9140(98)00377-4.

[119] N.G. Carpenter, A.W.E. Hodgson, D. Pletcher, Microelectrode procedures for the determination of silicate and phosphate in waters-fundamental studies, Electroanalysis 9 (2010) 1311-1317. https://doi.org/10.1002/elan.1140091703.

[120] A.W.E. Hodgson, D. Pletcher, Microelectrode procedures for the analysis of silicate and phosphate - towards practical procedures, Electroanalysis 10 (1998) 321-325. https://doi.org/10.1002/(SICI)1521-4109(199804)10: 5<321::AID-ELAN321>3.0.CO;2-A.

[121] K.K. Cavender-Bares, D.M. Karl, S.W. Chisholm, Nutrient gradients in the western north atlantic ocean: relationship to microbial community structure and comparison to patterns in the pacific ocean, Deep-Sea Res. Pt. I. 48 (2001) 2373-2395. https://doi.org/10.1016/S0967-0637(01)00027-9.

[122] H.W. Chen, L.D. Brindle, X.C. Le, Prereduction of arsenic(V) to arsenic(III), enhancement of the signal, and reduction of interferences by L-cysteine in the determination of arsenic by hydride generation, Anal. Chem. 64 (1992) 667-672. https://doi.org/10.1021/ac00030a018.

[123] S. Tsang, F. Phu, M.M. Baum, G.A. Poskrebyshev, Determination of phosphate/arsenate by a modified molybdenum blue method and reduction of arsenate by $\mathrm{S}_{2} \mathrm{O}_{4}^{2-}$, Talanta 71 (2007) 1560-1568. https://doi.org/10.1016/j. talanta.2006.07.043.

[124] M. Lacombe, V. Garcon, M. Comtat, L. Oriol, J. Sudre, D. Thouron, N.L. Bris, C. Provost, Silicate determination in sea water: toward a reagentless electrochemical method, Mar. Chem. 106 (2007) 489-497. https://doi.org/ 10.1016/j.marchem.2007.05.002.

[125] M. Lacombe, V. Garcon, D. Thouron, N.L. Bris, M. Comtat, Silicate electrochemical measurements in seawater: chemical and analytical aspects towards a reagentless sensor, Talanta 77 (2008) 744-750. https://doi.org/ 10.1016/j.talanta.2008.07.023.

[126] W. Giraud, L. Lesven, J. Jonca, C. Barus, M. Gourdal, D. Thouron, V. Garcon, M. Comtat, Reagentless and calibrationless silicate measurement in oceanic waters, Talanta 97 (2012) 157-162. https://doi.org/10.1016/j.talanta.2012. 04.011.

[127] D. Aguilr, C. Barus, W. Giraud, E. Calas, E. Vanhove, A. Laborde, J. Launay, P. Temple-Boyer, N. Striebig, M. Armengaud, V. Garcon, Silicon-based electrochemical microdevices for silicate detection in seawater, Sensor. Actuator. B Chem. 211 (2015) 116-124. https://doi.org/10.1016/j.snb.2015.01.066.

[128] M. Cuartero, G. Crespo, T. Cherubini, N. Pankratova, F. Confalonieri, F. Massa, M.L. Tercier-Waeber, M. Abdou, J. Schafer, E. Bakker, In situ detection of macronutrients and chloride in seawater by submersible electrochemical sensors, Anal. Chem. 90 (2018) 4702-4710. https://doi.org/10.1021/ acs.analchem.7b05299.

[129] J. Jonca, W. Giraud, C. Barus, M. Comtat, N. Striebig, D. Thouron, V. Garcon, Reagentless and silicate interference free electrochemical phosphate determination in seawater, Electrochim. Acta 88 (2013) 165-169. https://doi.org/ 10.1016/j.electacta.2012.10.012.

[130] C. Barus, I. Romanytsia, N. Striebig, V. Garcon, Toward an in situ phosphate sensor in seawater using square wave voltammetry, Talanta 160 (2016) 417-424. https://doi.org/10.1016/j.talanta.2016.07.057.

[131] C. Barus, D.C. Legrand, N. S triebig, B. Jugeau, A. David, M. Valladares, P.M. Parra, M.E. Ramos, B. Dewitte, V. Garcon, First deployment and validation of in situ silicate electrochemical sensor in seawater, Front. Mar. Sci. 5 (2018) 60. https://doi.org/10.3389/fmars.2018.00060.

[132] L.R. Adornato, E.A. Kaltenbacher, D.R. Greenhow, R.H. Byrne, High-resolution in situ analysis of nitrate and phosphate in the oligotrophic ocean, Environ. Sci. Technol. 41 (2007) 4045-4052. https://doi.org/10.1021/es0700855.

[133] G. Kim, Y.W. Lee, D.J. Joung, K.R. Kim, K. Kim, Real-time monitoring of nutrient concentrations and red-tide outbreaks in the southern sea of Korea Geophys. Res. Lett. 33 (2006) 338-345. https://loi.org/10.1029/ 2005GL025431.

[134] S.A. Jaywant, K.M. Arif, A comprehensive review of microfluidic water quality monitoring, Sensors 19 (2019) 4781. https://doi.org/10.3390/s19214781.

[135] V.R. Montiel, J.R. Sempionatto, B.E. de Avila, A. Whitworth, S. Campuzano, J.M. Pingarron, J. Wang, Delayed sensor activation based on transient coatings: biofouling protection in complex biofluids, J. Am. Chem. Soc. 140 (2018) 14050-14053. https://doi.org/10.1021/jacs.8b08894.

[136] S.Q. Liu, C. Yang, Y. Huang, X. Ding, Y. Li, W.M. Fan, J.L. Hedrick, Y.Y. Yang, Antimicrobial and antifouling hydrogels formed in situ from polycarbonate and poly(ethylene glycol) via Michael addition, Adv. Mater. 24 (2012) 6484-6489. https://doi.org/10.1002/adma.201202225.

[137] D.D. Chen, M.D. Wu, B.C. Li, K.F. Ren, Z.K. Cheng, J. Ji, Y. Li, J.Q. Sun, Layer-bylayer-assembled healable antifouling films, Adv. Mater. 27 (2015) 5882-5888. https://doi.org/10.1002/adma.201501726.

[138] C.H. Liu, J. Lee, J. Ma, M. Elimelech, Antifouling thin-film composite membranes by controlled architecture of zwitterionic polymer brush layer, Environ. Sci. Technol. 51 (2017) 2161-2169. https://doi.org/10.1021/acs.est.6b05992.

[139] C.H. Liu, A.F. Faria, J. Ma, M. Elimelech, Thin-film composite forward osmosis membranes functionalized with graphene oxide-silver nanocomposites for biofouling control, Environ. Sci. Technol. 51 (2017) 182-191. https://doi.org/ 10.1016/j.memsci.2016.10.040.

[140] T.A. Silva, M.R.K. Khan, O. Fatibello-Filho, M.M. Collinson, Simultaneous electrochemical sensing of ascorbic acid and uric acid under biofouling 
conditions using nanoporous gold electrodes, J. Electroanal. Chem. 846 (2019) 113160. https://doi.org/10.1016/j.jelechem.2019.05.042.

[141] S. Wu, X. Lan, F. Huang, Z. Luo, H. Ju, C. Meng, C. Duan, Selective electrochemical detection of cysteine in complex serum by graphene nanoribbon, Biosens. Bioelectron. 32 (2012) 293-296. https://doi.org/10.1016/j.bios. 2011.12.006.

[142] H.S. Qi, W.W. Zheng, X. Zhou, C. Zhang, L. Zhang, A Mussel-inspired chimeric protein as a novel facile antifouling coating, Chem. Commun. 54 (2018) 11328-11331. https://doi.org/10.1039/C8CC05298K.
[143] H.S. Qi, W.W. Zheng, C. Zhang, X. Zhou, L. Zhang, Novel mussel-inspired universal surface functionalization strategy: protein-based coating with residue-specific post-translational modification in vivo, ACS Appl. Mater Interfaces 11 (2019) 12846-12853. https://doi.org/10.1021/acsami. $8 \mathrm{~b} 22551$.

[144] Q.B. Wei, X.Q. Liu, Q.Y. Yue, S.H. Ma, F. Zhou, Mussel-inspired one-step fabrication of ultralow-friction coatings on diverse biomaterial surfaces, Langmuir 35 (2019) 8068-8075. https://doi.org/10.1021/acs.langmuir. 9b00421. 